


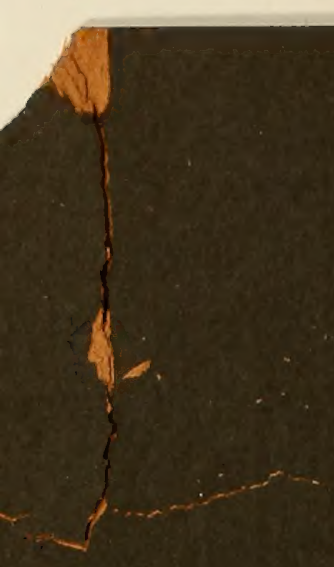




\section{LENGUAS ARGENTINAS}

SOA

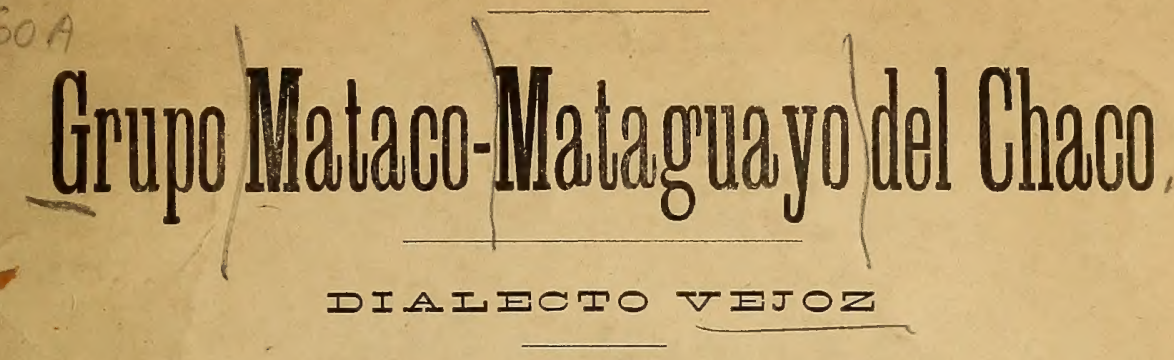

-

\section{VOCABULARIO Y APUNTES}

M. S. D' ORBIGNY

CON INTRODUGCION, NOTAS, ete.

SAMUEL A. LAFONE QUEVEDO M. A. $\mathbf{1 0 3 2 7}$

* de la Universidad de Camhridge

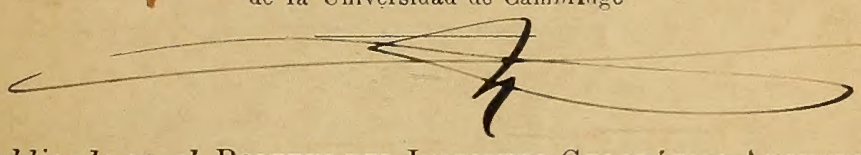

Pullicado en el Boletin del Instituto Geográfico Argentino Tomo XVII - Cuadernos 4.5 y 6

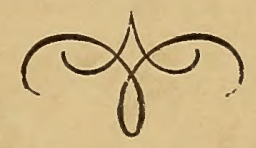

BUENOS AIRES

IMPLENTA “ROMA» DE JUAN GARBONE, GUYO $85 \%$

1896. 


$$
\begin{aligned}
& \text { PM5ill } \\
& \text { C408 }
\end{aligned}
$$

इ

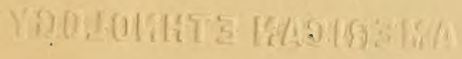

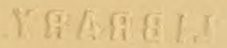




\title{
LENGUAS ARGENTINAS
}

\section{GRUPO MATACO-MATAGUAYO}

DEL CHACO

\section{DIALECTO VEJOZ \\ VOCABULARIO Y APUNTES}

M. S. D' ORBIGNY

con Introducción, Notas, etc.

POR

SAMUEL A. LAFONE QUEVEDO M. A.

de la Universidad de Cambridge

1895

IOS VHJOSHS

\author{
Estudio dedicado á mi amigo Lucien \\ INTRODUCGIÓN \\ Adam de Rennes. \\ I \\ Observaciones Generales
}

En otros trabajos se ha hecho notar que las Lenguas Americanas fácilmente se dividen en tres grupos: $1^{\circ}$ las que subfijan las partículas pronominales; $2^{\circ}$ las que prefijan las mismas; y $3^{\circ}$ las que se valen de ambos recursos gramaticales. De las primeras el ejemplo típico es el idioma llamado Quíchua; de las segundas el Guarany; mientras que de las terceras un ejemplo al caso sería el Mocoví y sus codialectos, que, de acuerdo con el señor Brinton y 
otros, se incluye en la gran familia Guaycurú, en realidad apodo general y no particular.

El Chaco, tanto el Argentino como el Boliviano, ha sido y aún es campeadero y cazadero de innumerables hordas de indios, nómades algunos, asentados otros, irreducibles aquéllos, más aptos para la civilización moderna éstos, y que también se distinguen por sus lenguas de tan diferente indole como lo son sus usos y costumbres étnicas.

De la lengua de los Mocovies y Tobas, tribus juries ó nómades, ya se ha tratado en la Revista del Museo de La Plata. Ellas pertenecen al tercer grupo, es decir, á aquel que se vale de las dos clases de afijos pronominales de relación personal. Este recurso gramatical, que á primera vista parece extraño, tiene una explicación muy natural: esas lenguas y sus codialectos se hallan encerradas entre la Guarany, que es prefijadora, y la Quíchua, subfijadora.

Encajadas entre estas lenguas de tipo Guaycurú, encontramos empero unos arrinconamientos lingüísticos muy curiosos, que por la colocación de sus afijos pronominales corresponden al grupo Quíchua, ó subfijador. De estos conocemos dos idiomas, el Lule de Machoni, y el Vilela ò Chulupí, que ambos han sido materia de estudios publicados en el Boletín del Instituto Geográfico.

No puede dudarse que las tribus que estos idiomas hablan sean restos de una gran nación. Su mansedumbre es un argumento en contra de la hipótesis que puedan haber entrado al Chaco como intrusos después de las invasiones Guaycurúes. Mientras no se pruebe lo contrario me inclino á creer que más ó menos corresponden á la raza Antisiana de d'Orbigny, y que sus afines los encontraremos entre los Mosetenes, Yuracares, etc.

Agotado por el momento el material con que se contaba para completar la descripción del grupo de que el Lule y Vilela son los dialectos conocidos, y suspendida la publicación de lo concerniente á los dialectos reconocidamente Guaycurúes, quedaba el vacío que correspondía á esa gran familia de dialectos á que se da el nombre de Matacos ó Mataguayos, Vejoses, Noctenes etc., de que si se quiere nada se sabia en la lingüística hasta que el Padre Remedi y el Ingeniero Pelleschi dieron á luz sus noticias, éste en 1881, aquél $€ n$ 1882. La publicación de esa obra por el señor Pelleschi fué causa de relacionarme con él, y de ello ha resultado el propó- 
sito de hacer un nuevo estudio en que se utilizarán los importantes apuntes lingüísticos que yacen escondidos en las carteras de este viajero observador.

Mientras el señor Pelleschi recorría sus notas y las reducía al orden, pude entablar correspondencia con los PP. Misioneros del Colegio de Tarija, y fuí obsequiado por el P. Fray Inocencio Massei con unos preciosos apuntes sobre el Nocten que forman parte de estas publicaciónes.

Más tarde empecé á cartearme con el Sr. Lucien Adam, el conocido Americanista de Rennes, en Francia, quien tuvo la amabilidad de remitirme una copia del MS Vejoz que se halla entre los papeles del viajero d'Orbigny, hoy en la Biblioteca Nacional de París.

Con este vocabulario y apuntes gramaticales se inicia el estudio sobre los dialectos Matacos que deben tratarse en este orden:

Nocten - según los apuntes del P. Inocencio Massei.

Vejoz — según el MS de d' Orbigny.

Mataco - según las publicaciones del P. Remedi.

Mataco - según los apuntes del Ingeniero Pelleschi en colaboración con el autor de este ensayo.

Es inexplicable que el erudito Hervas ro haya conseguido un ejemplar del Padre Nuestro para que Adelung lo hubiese podido incorporar en su "Mithridates"; pero ahí está el hecho, una de las lenguas más generalizadas de los Chacos Argentino-Bolivianos sólo figura como un nombre en el Catálogo de las Lenguas, y falta la muestra concreta en Adelung, porque no se había incluído en el Saggio Pratico de aquel autor.

No se crea que se trata de un idioma hablado por un puñado de indios en un rincon perdido de nuestro continente; muy al contrario, ias tribus Mataco-Mataguayas eran de las más numerosas que ocupaban el país cuando entraron los conquistadores; (1) los primeros Misioneros los evangelizaron y con un éxito muy superior al que les acompañó cuando pretendieron convertir a las naciones Frentonas ó Guaycurúes, á quienes sin embargo no ha cabido igual olvido.

Hoy empero que el Toba, el Mocoví y el Abipon son materia

(1) Lus Misioneros los estimaban en 60, C00 y más indios; hoy se habla de 20,000 . 
de publicaciones prolijas, se ha hecho necesario que ese estudio se haga extensivo al grupo Mataco; porque del más somero exámen resalta la relación lingüística que existe entre esta familia y el grupo Guaycurú, las diferencias léxicas no obstante.

A estas diferencias en los vocabularios puede atribuirse varias causas, y entre las más fecundas, esa costumbre de callar voces que hagan recordar los nombres de finados. Un vocablo nuevo trae á la cola una larga série de derivados. Otras palabras se pierden por el olvido que resulta de la falta de uso, y cuando renace la necesidad de emplearla, se busca un tema que haga la descripción de lo que se pretende nombrar; para esto nunca faltan raíces y partículas adecuadas.

Otra fuente importante de innovaciones léxicas es la mujer de otra raza. Rastros de esto más ó menos difundidos se hallan en las lenguas Americanas, pero en ninguna se distingue mejor entre las hablas varoniles y mujeriles que en las caríbicas. El General Mitre hizo notar esta especialidad tambien en el Chíquitano.

A algo parecido debe atribuirse esa riqueza de afijos pronominales de relación personal que campea en la América Meridional. No se concibe porque se hayan hecho algunas lenguas de tal labarinto de partículas de posesivación y flección verbal. Concedamos que ello entró por la diferencia entre el hablar del varón y de la mujer y todo se explica.

Al iniciarse el estudio de los dialectos Mataco-Mataguayos parecía como si se tratase de idiomas en que la articulación pronomino-personal era sencillísima. De los trabajos y observaciones de Pelleschi y Remedi no constaba que hubiese más de una serie de estas partículas; mas hoy con los apuntes del P. Massei sobre el Nocten por delante advertimos que, sea por la causa que se fuere, existe variedad de afijos, y que entre ellos reaparece esa $y$ dt $1^{a}$ persona que juega un rol tan importante en toda nuestra América.

Muy al principio de mis estudios comprendí que en el Mataco teníamos un idioma con afinidades Guaycurúes muy marcadas, y me fundaba en que la $\mathrm{M}$ de $2^{\mathrm{a}}$ y $\mathrm{L}$ de $3^{\mathrm{a}}$ persona encerraban una raíz pronominal común á las dos lenguas. Hoy que se sabe que el Mataguayo y sus codialectos titubean entre $N$ é $Y$ como índice de $1^{a}$ persona, nos vemos obligados á seguir la pista más allá, y odremos acusar al Toba de ser un dialecto Guaycurú con mez- 
cla de Mataco, 6 al Mataco de ser lengua en que el Toba etc. han entrado como elementos conquistadores.

Los nombres de las partes del cuerpo se distinguen de una manera radical de los que usan las naciones de tipo Guaycurú; pero las que nosotros llamamos partículas gramaticales son en muchos casos comunes á Matacos y Guaycurúes. Es un principio reconocido en la filología que las omofonías entre partículas y afijos gramaticales por pocas que sean, importan más que un catálogo largo de voces comunes. Es muy fácil tomar prestado un vocabulario entero, pero los afijos son los que dan el sello de nacionalidad. "They have encorralared the rodeo" es un ejemplo al caso. EI Inglés sala su discurso con infinidad de voces españolas, pero les aplica la sal y pimienta de su lengua, para que le sepa al idioma propio de su tierra.

Las tribus Mataco-Mataguayas aún son muy numerosas, pero debieron ser lo mucho más cuando entraron los españoles, por lo tanto interesa conocer su idioma en todos los dialectos. El Nocten nos demuestra lo indispensable que es tener en cuenta todas las diferencias dialécticas; pues en él vemos que se destingue entre los dos plurales de $1^{\text {a }}$ persona, cosa que no se había notado antes; al contrario parecía que estábamos obligados á incluir este grupo entre los que no conocían ese Nos que excluye al Tú ó Vos. Este descubrimiento es de grandísimo interés, por que es un eslabón que se encadena con los recursos gramaticales del mismo género en el Guaraní, lengua en que la $Y$ también entra como índice ó afijo inclusivo de $1^{\mathrm{a}}$ persona en plural: v. g. Yande-Nosotro y Vosotras. Ore-Nosotros, pero no vosotros.

Geograficamente el Mataco-Mataguayo y sus codialectos se interponen entre el grupo Guaycurú y el Quichuizante de la regiòn Andina en esta República. El P. Bárcena en su carta al Provincial bajo fecha 8 de Septiembre 1594, cuenta que los Lules, á quien él trata de Alábares, iban acabando con los Tonocotés ya antes de la conquista española; (1) se deduce pues que las tribus de raza Tonocoté, es decir, Mataco-Mataguaya, no podían resistir el empuje de los Juríes, Alábares, Lules, ó sean los Nómadas del Chaco.

Uno de los puntos curiosos en la historia y geografía de las Lenguas Argentinas es precisamente esta retirada de los Idiomas

(1) Relaciones Geog. Tomo II, p. LIV. 
Tonocotés, ó sea, Mataco-Mataguayos, á los confines de esta República, y la avanzada de los del tipo Guaycurú. Antes estas tribus llegaban hasta San Miguel y rodeaban la ciudad de Esteco; pero parece que los Mocovíes y otras tribus Frentonas ó Guaycurúes, remataron la obra empezada por los Lules y continuada por los conquistadores. Los que quedaron se absorberian en la masa de Indios Quichuizantes que aún pueblan las márgenes del Salado.

La publicación de estos Vocabularios y ensayos de arte allanará el camino á la prueba de que el Lule de Machoni no era el Tonocoté de Bárcena y Techo, porque podrán compararse las voces y sus recursos gramaticales, á la luz de esta noticia más, que hasta la fecha no ha resultado en la región aludida en las inmediaciones del Pilcomayo nación alguna, ni poco ni muy numerosa que acuse afinidades con el Lule de Machoni.

El P. Joaquín Remedi en su reciente monografía sobre los Matacos y su lengua (Salta 1895 ) dice que ha "hallado analogías y relaciones entre esteidioma (el Mataco) y el de los antiguos Tono"cotés, que residían en la frontera E de Salta etc. (p. 28)." Ignoro en que se funda el buen Padre para instituir el parangón; pero ello basta para hacer ver que éi como yo nos acordamos de Tonocotés, Abipones etc. cuando hablamos de Mataco-Mataguayos etc., y no de Lules de Machoni.

De que el Mataco es un idioma bastante mezclado se deja ver en las voces que dicen ( $(a g u a)$.

$\left\{\begin{array}{ll|ll}\text { Vejoz } & \text { Guag. } & \text { Mataco-Pelleschi. } & \text { Inotê. } \\ \text { Nocten } & \text { Innat } & \text { Toba } & \text { Netath } \\ \text { Mataco-Cardús. } & \text { Naatti é Innat. } & \text { Abipon- } & \text { Enópe. } \\ \text { Mataco-Remedi. } & \text { Huaj é Inot. } & \text { Mojo- } & \text { Une }\end{array}\right\}$

Heé-sí; Khá-no, son voces que también se hallan en la gran familia Guaycurù: Véanse las partículas $s a-$ no-del Toba; $s c a-$ no - del Mocoví. El subfijo qui-vaso continente-del Toba, Mocoví y Abipón, hi en Mataco, es otro ejemplo al caso.

Cuando les toque el turno á los Pronombres se hará notar la resaltante analogía que existe entre los de todos estos idiomas.

Hay una voz muy curiosa, común al Lule de Machoni, al Toba, Mataco, etc.; es Elé ò Helé - loro. Es una pista que seguida puede descubrirnos cual de las dos familias conoció y nombró primero á este pájaro.

En Lule este tema Elé tiene el sentido de-El del árbol,- que 
muy bien explica la idea de que los loros hablan imitando al hombre, y que se hallan en el bosque. No cabe duda que en Mataco, Mocoví etc. el subfijo lé indica individualidad también, pero el prefijo $E$ sería aquí más bien eufónico, y no me consta que el le pueda usarse sin una raíz determinante ó calificativa, $v$. g. Tucuman -lé-un Tucumano etc. Si resultase admisible esta derivación del tema Elé, este lé debería compararse con el otro lé en Pelépadre, persona etc.

Cuando llegue el momento de comparar el Mataco con el Lule acaso se descubra algo que nos indique la interrelación que pueda existir entre estos dos idiomas. Para mi lo admirable es que el Mataco tenga voces Lules, mientras que en su mecanismo gramatical son muy diferentes; por el otro lado el Mataco está bien distante del Toba, Mocoví etc. en su lexicología, y no obstante sus partículas gramaticales se parecen mucho, cuando no son idénticas.

II.

\section{GEOGRAFİ DEL VEJÓz.}

Antes de proceder á escribir estos apuntes me dirigí á mi amigo Fray Doroteo Gionnecchini del Colegio Misionero en Tarija, con el objeto de averiguar la ubicación exacta de las tribus Vejoses, y en seguida se reproduce lo que me contestó al respecto en su carta del 18 de Febrero de 1895.

«Tocante á los Vejoses, le diré, ningún pueblo de ellos está ubicado en el territorio Boliviano. Vejoses, Matacos y Mataguayos es la misma familia ó tribu con algunas pequeñas distinciones de provincialismo; y por nuestras fronteras Bolivianas se ignora por completo el nombre de Vejoses, y tan solamente se conoce á esa tribu con el nombre general de Matacos, y el particular de Noctenes.

"A fines del siglo pasado, este Colegio de Misioneros fundò en Centa (Oran Argentino) una misión de Mataguayos y Vejoses. Los Mataguayos eran los que ocupaban la márgen derecha del río Bermejo, y los Vejoses eran los que ocupaban la izquierda y que llegaban hasta Itiyuru de Caiza: cuyos descendientes esparcidos por el Itiyuru aún ahora se conocen con el simple y general nombre de Matacos del río Seco. 
«En este punto del río Seco á pocas leguas fué menester trasladar los Vejoses de la misión de Centa, y por diversas razones fundarles una misión por separado de los Mataguayos, que duró 5 o 6 años, y que por su volubilidad, fué menester abandonarla, é incorporarla de nuevo á la de los Mataguayos de Centa, de la cual no quedó otra señal que la que tiene aún hoy de "La Reducción» del río Seco. "Yo he pasado por ese punto, y dormí, en el punto que fué la iglesia, que ahora es un corral.» El capatáz pues de dicho lugar, me aseguró que cavando para plantar los postes, ú horcones, del corral, dió con los cimientos de la iglesia.

«De modo que el lugar topográfico del territorio de los Vejoses se debe poner desde el río de Oran, hasta el río Seco, ó lo más hasta Itiyuru por toda aquella zona que mira al O. ó sea á la serranía.

«Empero en cuanto á su extensión al E. y NE. no le sabría indicar los límites, porque desconozco esos lugares, y solo sé que á todos esos indios del Chaco Argentino y Boliviano los llaman en general Matacos.

"Lo que puedo asegurar es que la tribu Vejoz, nunca ni en ningún tiempo ha pertenecido al territorio Boliviano, y mucho menos pertenece ahora, con la nueva demarcación de límites que acaban de señalar."

Con esta carta y otra del mismo Padre, á propósitos de los Matacos en general y Noctenes en particular nos es fácil levantar el mapa lingüistico de este grupo de idiomas. La Geografía de las Lenguas es importantísima para la clasificación acertada de estas: muchos puntos oscuros de etnología y filología se esclarecen con la simple ubicación de las tribus en su propio lugar; porque así se ve como las omofonías entre dos lenguas, puedan deberse á contacto geográfico.

Tiempo hace que con mi amigo Pelleschi hemos hablado de levantar un mapa lingüistico de la República entera; empezaremos pues con este de los Vejoses ó Matacos cuidando de incluir las tribus y naciones de otras hablas que los rodean.

La carta del P. Alonso de Bárcena á su Provincial nos servirá de mucho para saber hasta donde entraban los Tonocotes ó Matacos ahora 300 años; porque á no dudarlo estas tribus se han ido retirando al NE. habiendo desaparecido por completo de lo que fué jurisdicción de Esteco. 
III.

Usos, costumbres etc. de los Vejoses.

No es mi propósito decir nada acerca de este punto por ahora, en razón de que lo dejo para cuando le toque el turno al Mataco. Todos los autores están contestes que Vejoses, Noctenes, Mataguayos y Matacos son una sola cosa á este respecto, y lo que diga de unas tribus puede aplicarse á las demás evitándonos así de prolijas repeticiones.

IV.

La lengua de los Vejoses.

Aún cuando el MS no nos lo hubiera asegurado está de manifiesto que la lengua Vejosa es un dialecto del grupo Mataco-Mataguayo, y cuando entremos á tratar de los Vocabularios recogidos por Pelleschi compararemos las voces unas con otras, para que se haga cargo el estudiante de como se diferencían entre sí los vocablos en el mismo grupo de idiomas.

Esto en tésis general. Ahora por lo que respecta al dialecto este Vejoz nos ofrece algunas especialidades muy dignas de ser tenidas en cuenta, por cuanto ellas nos enseñan como pueden emparentar con otras mucho mas remotas en más de un sentido lingüistico. Vamos á los ejemplos.

Todo estudio mío parte del principio que la comparación debe empezarse por los pronombres y sus partículas, sin perjuicio de que los resultados se sometan á otras pruebas á posteriori. Bien pues, sabemos que el Vejoz es lengua del grupo Mataco, pero nos sale al encuentro esto en los pronombres personales:
Vejoz.
1 Yaam
Mataco en general.
2 Aam ó Japeem
3 Jape ó Atadchi
1 Nuslam ó Nujlam etc.
2 Ham, Am, ó Em
3 Jaem, Lam, Slem etc.

Esta variante de la primera persona llama la atención, porque se separa del tipo Mataco que gira al rededor de una $n$, ó sea, un sonido nasal con otro gutural, á veces sibilado. Yo no soy de los que aceptan el argumento de las casualidades, sin que por eso diga que lo rechazo, una vez que se pruebe; por eso, busco la explicación 
en alguna influencia ya sea extraña al grupo, ya al dialecto este, pero que se pueda derivar de algún orígen verosimil.

Pues bien, mis escursiones lingüisticas en los autores que corren impresos, y en los MSS de las colecciones particulares, me han suministrado pistas, que por cierto no se han hechado en saco roto. A la prueba me remito.

Adelung en su Mithridastes t. III. p. 490 reproduce una oración en Payaguá de la que resultan los siguientes pronombres:

$$
\begin{aligned}
& \text { Yam - Yo Me, Mio. } \\
& \text { Ham - Tü. Tuyo. }
\end{aligned}
$$

Aquí tenemos el Yaam-yo-y;

Aam - tú, — del Vejoz.

El Payaguá este y el de Mansfield parece que son codialectos con el Lengua segun se desprende del Vocabulario manuscristo de Cerviño, hoy en la Biblioteca del General Mitre: en este hallamos que Yopjas dice - este - que se compara bien con el Jape del Vejoz.

Con este dato seguí adelante el cotejo, y no dejé de hallar otros temas comunes á las dos lenguas, que debo pasar por alto hasta mejor ocasión, limitándome solo á un ejemplo, que citaré por su importancia.

En Lengua tenemos:

$$
\begin{aligned}
& \text { Ueegh - Agua. } \\
& \text { Guas - Lluvia. }
\end{aligned}
$$

En Vejoz:

$$
\text { Guag - Agua . }
$$

Acordemonos que el Mataco conoce otra voz que dice agua y es, Inote; mientras que variantes como Huag de Remedí se apróximan aún más á los temas del Lengua.

Omofonías como esta no deben atribuirse á la casualidad; y como los Lenguas y Payaguaes pueden llamarse naciones limítrofes de los Matacos, nos es lícito suponer que el Vejoz sea un codialecto del Mataco en que ha influído para mucho el abolengo de tipo Lengua-Payaguá.

El Lengua y Payaguá pertenecen á la gran familia Guaycurú, que, como varias veces se ha dicho ya, incluye tambien el Toba, Mocoví, Abipon etc.; desde luego conviene ver si aquí también encontramos rastro del Vejoz. Daré algunos ejemplos que yo creo al caso: 
Vejoz

Guaycurú-Gili

Nolagui

Boca Yoladî

Castelnau

(1)

Nocagliguiu Lengua Nogueligui

Coniala

Guag

Agua Niogodì

Codoketi

Nìogo.

Algo hay en todo esto que apunta en dirección á contacto lingüistico. Los temas de Gilii y Castelnau están incrustados con afijos pronominales, al grado que la raíz del primero debe buscarse en Ola, del $2^{\circ}$ en Gueligui acaso Gueli.

Cuando le toque el turno al Mbaya, llamado Guaycurú, tendré mucho que decir; mas por ahora baste que reproduzca de Adelung (Mit. t. III p. 482) los pronombres y sus afijos:

Siugular

1 E 6 Eo

2 Acami $\delta \mathrm{Am}$

3 Jyobate
Plural

1 Oco

2 Acami diguagi

3 Jyobate diguagi.

\section{Posesivos.}
$1 \mathrm{Y}-\dot{\delta} \mathrm{Yn}$
$2 \mathrm{Ca},-\mathrm{Can}-6 \mathrm{Cad}$
$3 \mathrm{~L},-6 \mathrm{~N}$

1 Co, - Con-o Cod-
2 Como el sing
3 Con diguagi.

Prefijos verbales.

\section{$1 \mathrm{Ya} \sigma \mathrm{Ye}$ \\ 2 A $6 \mathrm{E}$ \\ 3 Da 6 De.}

Compárense estas series con las de nuestro Vejoz que son Yaan - Yo.

Aam - Tú.

Jape - El otro.

Prefijos de Posesivación.

$1^{\text {a }} \mathrm{Ya} \delta \mathrm{Y} ; 2 \mathrm{~A} \sigma \mathrm{E} ; 3 \mathrm{~L}$.

En el M S faltan los afijos verbales.

De aquí resulta una cosa curinsa. El Vejoz, idioma del grupo Mataco, tiene mecanismo pronominal casi idéntico con el del grupo

(1) Gilii y Castelnau, dos autores que dan vocabularios Guaycurúes. 
Guaycurú, y, sin embargo su vocabulario está muy distante de presentar las mismas analogías. Sin duda temas comunes á los dos idiomas podrán hallarse, pero las omofonías, que son la regla entre los pronombres, apenas si son la excepción en lo demás de los repetidos vocabularios. Ahora el punto en cuestión, sería este: ¿debemos admitir el parentezco lingüistico en razón de lo primero, 6 rechazarlo en razón de lo segundo?

Cada cual resolverá, este punto como quiera, y podrá haber variedad en la apreciación de la proporción en que puedan entrar elementos de un idoma en el otro; pero esto creo, que se tendrà que admitir, que las omofonías pronominales resultan de comunidad de orígen y no de la casualidad.

Por otro lado están ciertos rasgos étnicos que comprueban la diferencia de razas. Los Indios del grupo Guaycurú son indomables; los del grupo Mataco son mucho mas accesibles á las influencias de la civilización Europea. Quiere decir pues, que naciones mas inmediatas á la raza Quichuizante fueron sojuzgadas por tribus Guaycurúes, Juríes ó Nomadas que adoptaron el vocabulario pero impusieron su organismo gramatical en que se incluye la articulación caraterística.

Igual cosa sucede en Europa: El inglés tiene un vocabulario bien distinto del castellano, en cuanto á la parte Inglesa, que no es ni Latin, ni Latin afrancesado; los pronombres empero son idénticos en el singular, ex. gr.

$$
\begin{aligned}
& \text { Yo - Y. } \\
& \text { Tú - Thou. } \\
& \text { Es - He. }
\end{aligned}
$$

Este Se el Se en dáselo.

Hasta aquí creo que nadie se ha apercibido de esta regla de lingüistica Argentina, que lenguas con pronombres y partículas pronominales de idéntico valor fonético pueden servirse de vocabularios que en lo demás nada tengan en común. Lícito sería suponer que estos temas resulten de combinaciones léxicas, sea por la razón que se fuere; pero para mí lo más racional sería la hipótesis que una ola invasora había conquistado toda esa parte de América en que aún campean la raza Guaycurú y sus afines, y que al imponer su articulación pronominal adoptó por mayor el habla de los conquistados, tribus estas que en comparación de las otras podrían llamarse autóctonas. 
De la misma manera el Aryano chocó con razas preexistentes en el Mundo Viejo, y del choque resultaron el Sanscrito en Oriente; el Griego, Latin etc. en el Occidente.

$\measuredangle$ De dónde resultó que el Francés aun dice Mon y Portugués Miño? ¿Del Latín ó del Tedesco?

Una vez que se hayan examinado bien todos los codialectos de los grupos Mataco y Guaycurú podremos ampliar este curioso capítulo; pero por ahora me limitaré á hacer constar que en el Vejoz tenemos un idioma intimamente ligado con las lenguas Guaycurúes en la parte pronominal, lo que no se reproduce en lo general de sus vocabularios. Lo propio se advierte en los demás codialectos de este grupo.

Los codialectos Guaycurúes en muchos casos cambian de voces: un idioma, el Abipon por ejemplo, puede usar un 50 por ciento de vocablos extraños al Toba, Mocoví etc.; pero apesar de esto sus pronombres, su articulación, su morfología, su fonología, ese otro $50 \%$ todo denuncian la comunidad de orígen lingüistico. En el Mataco digamos que solo se halle un 10 por ciento de voces comunes al tipo Guaycurú; pero este $10 \%$ incluye los pronombres y partículas allegadizas; no podremos pues desconocer el parentezco en este caso como en aquel. Este principio reconocido en dos ó más idiomas establecerá el cánon que el encadenamiento de las lenguas americanas debe buscarse ante todo en sus pronombres.

Es en mérito de esta consideración que doy tanto valor al estudio de los idiomas del grupo Mataco-Mataguayo. Es tan facil probar el orígen común en lo que tienen de semejanza con los del grupo Guaycurú, y á la vez está tan de manifiesto que los respectivos vocabularios responden á diferentes abolengos, que cualquiera se convence de que es así y se halla preparado para reconocer el cánon en casos en que las analogías están algo mas encubiertas, ya sea por complicación de mezclas, ya por morbosidad de sonidos, ya por cualquier otra causa.

Con el correr de los siglos las voces cambian de valor léxico cosa que se prueba facilmente en lenguas que tienen historia, es decir, de que se puede hacer filología. En América no cabe este procedimiento, pero por analogía lo podemos admitir, y aún probar por medio de los codialectos.

Hay un hecho más que puede citarse: cada lengua que se descubre, que pertenece á algún grupo conocido, nos facilita el enca- 
denamiento con otras afines ó semi-afines, porque en las diferen cias dialécticas muchas veces hallamos el eslabón que falta. Ahora 5 años no sospechaba yo que la $Y o r$ fuese también índice de la $1^{a}$ persona en el grupo Mataco. Me párecía extraño que ello no fuese así, y no me explicaba la desaparición de este elemento primordial en una serie de pronombres que en lo demás era Guaycurù. El obsequio del P. Massei me enseñó que por lo menos el Nocten usaba la $I$ en sus afijos verbales, y más tarde el Vejoz vino á comprobar la existencia de este índice en nuestro grupo. La posesión de dos ó más series de afijos pronominales de relación personal era un argumento más en favor de que el Mataco podía ser un dialecto degenerado del Guaycurú; como que, si etnicamente admitimos que aquellos son de la raza de estos, tendrémos que conceder también que, en la mezcla con aquellos, éstos hayan perdido juntamente con la lengua algo de su natural fiereza.

Sabemos, por el Padre Bárcena, que los Lules, Alarabes del Aconquija, esos Juries de la Conquista, estaban exterminando á los Tonocotés de la región ó cuenca de Esteco etc. En el Tonocoté debemos buscar esa base que, como habla mujeril, pudo formar el idioma de los Mataco-Mataguayos en la parte que se diferencia de las lenguas de tipo Guaycurú.

V.

\section{El MS Vejoz.}

El MS del Vejoz es anónimo, á juzgar por la compulsa que yo tengo, y que me fué mandada por el señor Lucien Adam de Rennes, en Francia. Consta de un regular vocabulario y de 5 carillas de apuntes gramaticales. inicial.

En el vocabulario los verbos están por separado bajo cada

En la presente monografía se ha reproducido la parte gramatical con notas que separan del texto así, [ - ]. El vocabulario, que está en la forma de Castellano-Vejoz se ha reducido al orden estrictamente alfabético, sin distinción de palabras como en el original, y para el cotejo de las raíces se ha invertido al Vejoz-Castellano también. Esto es indispensable para todo estudio acertado de una lengua. Este procedimiento tan puramente mecánico sue- 
le aclarar más de cuatro misterios, facilita el descubrimiento de las raíces, la forma de las partículas temáticas y nos da pistas importantes para determinar la fonología y la morbosidad de ciertos sonidos en cada lengua.

Y á propósito de la fonología es punto que no se tocará en este segundo tratado, porque se reserva para el estudio final del Mataco de Pelleschi. En primer lugar nos faltan datos, en segundo esperamos poder comparar los varios vocabularios, y para ello es necesario tenerlos á la vista. Esto no obstante conviene tener presente que los idiomas todos del grupo Mataco-Mataguayo usan la $l$ por $r$, confunden la $j$ y la $s$, y fácilmente dejan de hacer sonar la $m$.

También debe sospecharse cierta sustitución de estos sonidos unos por otros:

$$
\mathrm{m}, \mathrm{u}, \mathrm{v}, \mathrm{b}, \mathrm{p} \text {. }
$$

Con estas advertencias pasaremos á hacernos cargo de lo que es el Vejoz, según el MS, que nos ha conservado el viajero Alcides d'Orbigny, y que probablemente procedió de esa misma Reducción del Río Seco á que se refiere el Padre Gionnecchini.

\section{[FOJA 55 DEL MS] \\ Arte de la lengua Mathaguaya: Del Nombre.}

Tiene esta lengua Mathaguaya, Bejosa y Mataca, que es lo mismo, porque las tres hablan un mismo idioma, las ocho partes de la oración... como la lengua latina... aunque no con la perfección que ésta en todas:

$$
\begin{array}{c|l}
\text { Noon - hombre } & \begin{array}{l}
\text { Signag - perro. } \\
\text { Is - bueno }
\end{array} \\
\text { nisua - malo. }
\end{array}
$$

[Se ve aquí que nisua es una simple negación de is, y desde luego, que Nó Ni y $\mathrm{Ua}$ son partículas negativas; sobre todo las dos primeras. Ver el Vilela.

$\mathrm{Ed}]^{*}$

Noon is. - Indio bueno.

Snag Guajalin (u?) - perro ligero.

[ El adjetivo se posterga, á la inversa del Quichua. Noon ante todo dice "hombre"; se deduce pues que Bejoso es el nombre que otros dan á estos Indios. Ed.]

\footnotetext{
* Todo aumento al original irá separado en esta formu.
} 


\section{[ GÉNERo ]}

[ Desde que Yase es - hija - y Yasa - hijo - es lógico deducir que en Mataco, como en Mocoví etc., la terminación $e$ debe reputarse de femenino. Una vez más llamaré la atención á que, en los pronombres de tipo Mocoví etc. al principio de los temas e sería de masculino y a de femenino, v. g. Adassó, sería-aquella, parada; Edasó - aquel, parado etc., etc.

Este caso más puede referirse del Mocoví:

Lactee - La madre.

Lectâa - Ël Padre.

Aquí vemos un intercambio curiosísimo, pues se emplean los dos recursos, á saber: $a$ inicial y $e$ final, para femenino; $e$ inicial y $a$ final, para masculino. Ed.]

\section{[-§ Número y caso ]}

Los nombres todos son indeclinables. Sólo el plural se distingue del singular por su diversa terminación.

Sin. Nom. Y Noon - El hombre.

Gen. $Y$ Noon - del hombre.

Dat. $Y$ Noon - para el hombre.

Plur Nom. Y Nolas - los hombres.

[ Mucho más pudo haberse dicho acerca de este paradigma. En el se advierte un $Y$ pronominal de $3^{\text {a }}$ persona, tan general en el Chaco (ver Arte Mocoví) que se halla también en los patronímicos Cacanos v. g. Camis ay, Huanchicay etc., y que yo traduzco-él de Camisa, el de Huanchica etc. En Quichua y Aymará es también subfijo de $3^{\text {a }}$ persona. Las proyecciones de esta partícula alcanzan hasta el Viejo Mundo.

Parece que las en este caso sea el subfijo de pluralidad. Remedi dice que las partículas pueden ser $l, i$, ó $s$, según el caso. Ed. ]

La casa del Padre es buena - Pale Lubucua is.

[ Casa es Lobuque y Hoet. El prefijo Lo sin duda es de relación de $3^{\text {a }}$. En Toba Nohich y Lavo dicen-Casa. Ed. ]

[ Algunos Plurales.

$$
\begin{aligned}
\text { Lel } & \text { - Caracol - Lelises. } \\
& \text { - Calzones - Nolacpois. } \\
& \text { - Cañas - Canujuüs. Ed. ] }
\end{aligned}
$$


El caballo de JuAN-Juan Latag.

[ En esta, como en casi todas las lenguas, se acostumbra usar el posesivo por construcción: aquí como en los más de los casos la voz que indica el poseedor de la cosa precede á la de lo poseído. En Araucano la regla se invierte. Ed.]

\section{Del Pronombre.}

Los pronombres primitivos son los siguientes:

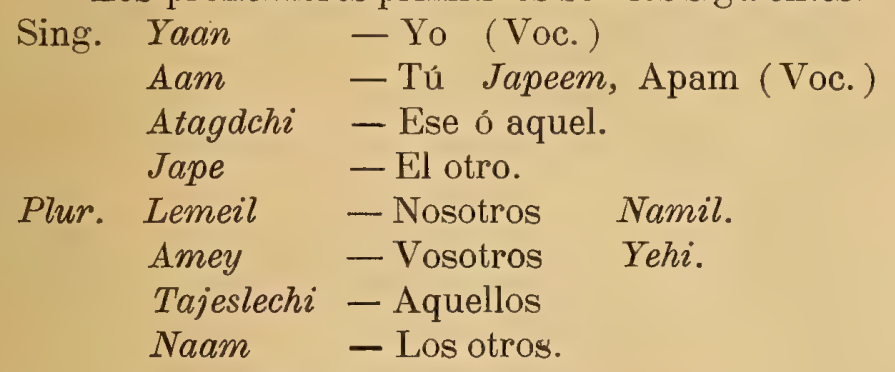

Todos estos son indeclinables.

[ Daré en seguida las equivalencias dialécticas de cada persona:

\begin{tabular}{|c|c|c|c|c|}
\hline VEJOZ & Mataco Remedr & Mat. Pelleschi & Mataco Cardús & Nocten \\
\hline $\begin{array}{r}\text { Sing. (1) Yaan } \\
\text { (2) \{ Aam } \\
\text { Japeem }\end{array}$ & $\begin{array}{l}\text { (1) Nuslam } \\
\text { (2) Am. }\end{array}$ & $\begin{array}{l}\text { (1) Noch-lam + } \\
\text { (2) Am ó Ham }\end{array}$ & $\begin{array}{l}\text { (1) Nujlam } \\
\text { (2) Em }\end{array}$ & $\begin{array}{l}\text { (1) Noslem } \\
\text { (2) Em }\end{array}$ \\
\hline (3) $\left\{\begin{array}{l}\text { Atagdchi } \\
\text { Jape } \\
\text { Plur. (1) }\left\{\begin{array}{l}\text { Lemeil } \\
\text { Namil }\end{array}\right.\end{array}\right.$ & $\begin{array}{l}\text { (3) Lam } \\
\text { (1) Nusiamil }\end{array}$ & (1) Noch-lam-il & $\begin{array}{l}\text { (3) Jaem } \\
\text { (1) Nos leen mei }\end{array}$ & $\begin{array}{l}\text { (3) Slem } \\
\text { (1) Inneemel, Ine } \\
\text { Nosleemel Exc. }\end{array}$ \\
\hline (2) $\left\{\begin{array}{l}\text { Amey } \\
\text { Yehi }\end{array}\right.$ & (2) Amil & (2) Amil-á & (2) Emei & (2) Emei \\
\hline (3) $\left\{\begin{array}{l}\text { Tajeslechi } \\
\text { Naam }\end{array}\right.$ & (3) Lamil & & (3) Aemei & (3) Sleemel \\
\hline
\end{tabular}

No dice el autor de los apuntes si en este dialecto se distingue entre el Plural Exclusivo y el Inclusivo; fijándonos empero en el Nocten debe sospecharse que algo de esto haya en las variantes Lemeil y Namil. Mejorándose de datos podrá esclarecerse este punto de tanto interés. Ed.] 


\section{[ LA $1^{\text {a }}$ PERSONA.}

Aquí vemos asomar el índice $\mathrm{Y}$ de $1^{\text {a }}$ persona tan conocido en el Caribe, Guaraní, Mocoví y demás lenguas de este grupo. En el Nocten también lo advertimos, pero no con la misma franqueza que aquí.

Para evitar repeticiones recomiendo los capítulos que tratan de los pronombres en mi "Arte Mocoví », sobre todo la P. XLII de las Notas. Allí se verá esta curiosa serie:

Yam (Yo), Ham (Tú) Payaguá;

y Yopjas (El) Lengua.

Y del Toba:

Ayem ( Yo ), Ham ó Am ( Tú), Hedago ( El).

Estas son algo más que coincidencias, que nos sirven para corroborar la sospecha de que los dialectos Matacos tienen mucho en común con el grupo Toba-Guaycurú.

En el vocabulario.

$$
\begin{array}{r}
\text { Yaam - ámi } \\
\text { Yapian - Yo soy. Ed.] } \\
-\S \mathrm{C}- \\
\text { [LA 2 } 2^{\mathrm{a}} \text { PERSONA. }
\end{array}
$$

El Aam es tan regular que basta referirme á los dos párráfos anteriores. No es posible dudar que este pronombre, sea en su forma Am, Ham, $\delta$ Kham, proceda de un solo orígen. Lo que llama la atención es su universalidad en toda la América. Véase "Arte Mocoví» ubi supra.

El Japeem debe compararse con el de $3^{\text {a }}$ Jase - el otro. Japeem parece que en realidad es-tú eres-Ed.]

$$
-\S \mathrm{D}-
$$

\section{[ LA $3^{\text {a }}$ PERSONA.}

En estos pronombres es donde más variedadad cabe. Véase $\S \mathrm{B}$ y cotéjense los de $3^{\mathrm{a}}$ persona. En cuanto al Jape véase el an- 
terior, y también el Mataco de Cardús Jaem. La $\mathrm{S}$ del Nocten Slem sin duda es sibilación de la J y representa unà formà Jlem. La $J=S$ eś una ecuadción notoria en estas y muchás otras lenguas. Ed.]

$$
-\S \mathrm{E}-
$$

\section{[LA' $1^{a}$ PERSONA EN PLURAL.}

Las 5 variantes del cuadro §A están llenas de instrucción. Ya se he dicho que las dos variantes acaso respondan á dos plurales, uno que incluye otró que excluye al que oye, pudiendo aquel ser Lemeil y este, Namil siguiendo la analogía del Nocten. Ed. ]

$$
-\S \mathrm{F}-
$$

\section{[ LA $2^{\mathrm{a}}$ PERSONA DEL PLURAL}

$$
\text { Amey - vosotros. }
$$

Todo aquí es regular. Los dos Dialéctos Argentinos terminan en el plural $l$, los tres Bolivianos en el otro $i$. Posible es que este encierre un sonido de $l$ morboso. Véase el "Arte Mocoví" ut supra.

La variante Yehi puede encerrar un error de transcripciòn.

Ed. ]

$$
-\S \mathrm{G}-
$$

\section{[LA $3^{\text {a }}$ PERSONA DEL PLURAL.}

Tajeslechi - aquellos. Naam - los otros.

Si por J escribiésemos $\mathrm{H}$ se explicaría mejor un plural Aemei del singular Jaemi. Por lo que respecta al Tajeslechi, debe advertirse, que muchos de estos naturales no pueden distinguir entre F. y J. para ellos el que huye - se Juga, y el que pierde la camisa á la taba la fuega.

Por lo demás el tema Tajeslechi incluye el Sle del Nocten.

Cuantas dudas no se esclarecerán cuando aumentemos la tabla de las variantes dialécticas y conozcamos algo más de estos interesantes idiomas. A lo que se ve todos ellos se encadenan unos 
con otros de la manera más admirable. Nosotros nos confundimos por la falta de eslabones, y por eso á veces nos sentimos inclinados á exclamar en nuestra desesperación.-Todo esto es inorgánico, es el Bable de los animales.-Creo firmemente que está muy lejos de ser así. Una recopilación científica de todas las Len. guas Americanas daría resultados sorprendentes, porque la tabulación de ellas por grupos y regiones, con más la estadística de su importancia relativa, nos abriría los ojos á senderos vastos de conocimientos exactos en que ni hemos soñado.

El Dr. Daniel Brinton de Filadelfia, autoridad en la materia, no da la importancia que yo á los pronombres, y se funda en que parece haber confusión entre los de $1^{\mathrm{a}}$ y $2^{\mathrm{a}}$ persona, en muchos casos. Que sea esto así: supongamos que los abolengos A y B fuesen los que tal hiciesen, se cae de su peso que los descendientes de uno y otro tronco debieron claudicar del mismo pie. A esto se limita el alcance de mis argumentos, por ahora: sea cual fuere el origen del pronombre, mis agrupaciones responden al tronco A ó al tronco $B$ por razones afínicas ó consanguíneas, de alianza ó de descendencia. Ed.]

Se llama la atención al subfijo chi en los siguientes:

Tajeslechi - aquellos.

Atagdchi - ese 6 aquel.

Atalechi - Del otro.

Yocachi - Allá.

Ydcachi - Allá, no lejos.

Yllachi - ¿Quién?

Los demostrativos de lugar son estos, y son adverbios locales:

Cauna - Aquí
Ydcachi - Allá
Ydycadni - Allá lejos
Quic - Adonde está
Qui - Adonde, de donde.
Yocachi - Allá

| Yllachi-Allí.

- no muy lejos.

Ynimicuccho-Por Allí. Quinunucuc-Por donde.

Yocachi - Allá

Adviértase que si à algunos de estos adverbios locales se les añade alguna partícula hacen oración y significan lo mismo que si túviesen verbo, v. g. 
Quicha? - ¿Dónde está ?

Quila joje? - ¿Adónde vas?

Quila tagli? - ¿ De dónde vienes?

También este adverbio Qui (si) se le arrima á algún verbo se le añaden estas sílabas.

Quijatigle nann ( u ?) 1. Yapi ? \&Cuando vendrás? ó ¿te irás ?

$$
-\S \mathrm{I}-
$$

Como pronombres y adverbios interrogativos pueden citarse los siguientes:

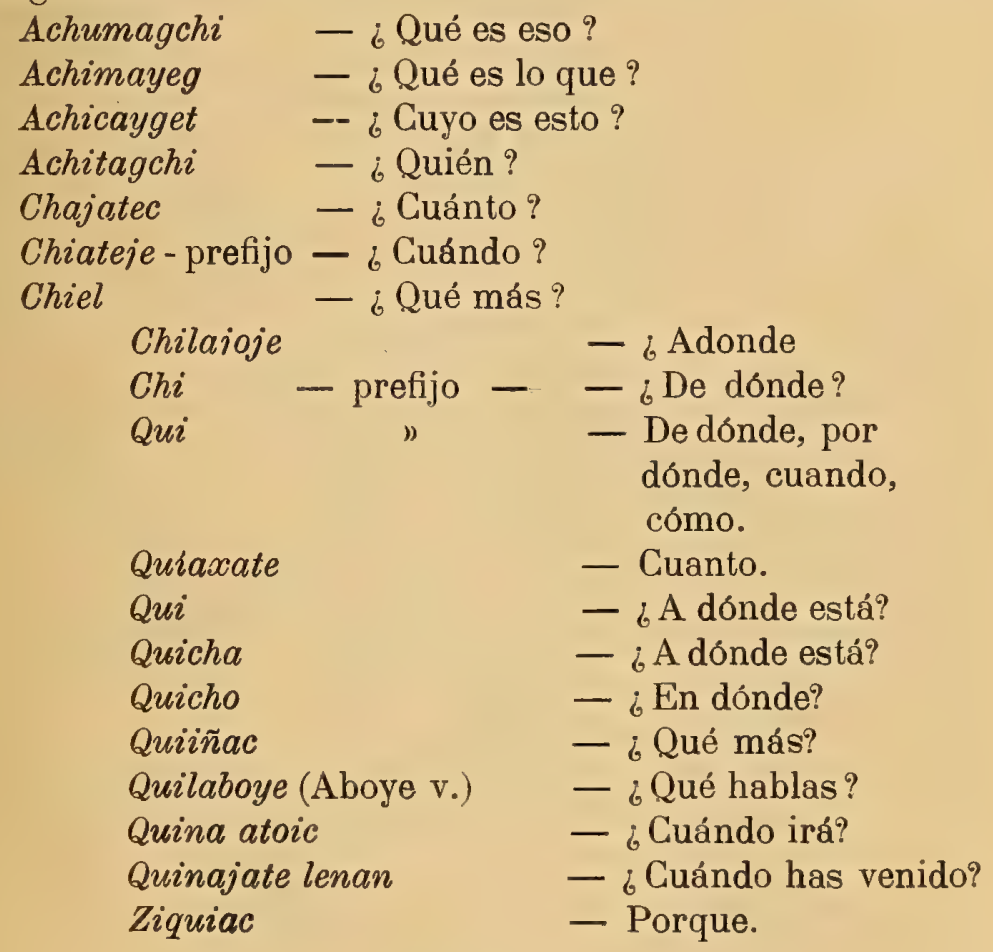

\section{Los Pronombres Posesivos}

Los pronombres posesivos como: mio, tuyo, suyo-en esta lengua no son dicciones completas, sino que se hacen añadiendo 
ciertas partículas ó letras con las cuales significando la posesión queda dicha posesión hecha.

Las partículas son:

$$
\begin{aligned}
& \text { Nocatági - Mio } \\
& \text { Nocaiguet - Nuestro }
\end{aligned}
$$

$\left.\begin{array}{l}\text { La } \\ \text { Pl Lay }\end{array}\right\}$, cuando es viviente la cosa que poseemos, perro, caballo, etc. y significa: suyo ó de aquel.

$\left.\begin{array}{l}\text { Cay } \\ \text { Pl } \text { Caigas }\end{array}\right\}$

cuando no es viviente la cosa que se posee, como: agujas (abujas en el texto), achas, etc. Pero se advierte que siempre se declara el nombre primero del que posee, y así dicen: Pe. la Francisco caigi-ese de el Padre.

$\begin{array}{cl}\text { Y aaiñac } & \text { - mis parientes } \\ \text { aainac } & \text { - tus parientes } \\ \text { Leey } & \text { - mi tío. } \\ \text { é Ley } & \text { - tu tío. } \\ \text { Athila } & \text { - tu hermano. } \\ \text { Achinic } & \text { - el menor. }\end{array}$

Nochita, Nolas - tu hermana (error sin duda por mi etc. Ed.] $Y$ asa - hijito mío.

Aasa (1) - hijito tuyo.

Y leés - mis hijos.

Aleés - tus hijos.

[ Este cuadro se ha formado de voces sacadas del Vocabulario. Allí se ve que,

Y, y No, son prefijos de $1^{\mathrm{a}}$ persona.

A el de $2^{a}$ persona.

L con alguna vocal, el de $3^{\text {a }}$ v. g. L La Francisco.

\begin{tabular}{l|l} 
Mat. Rem. & Mat. Pell. \\
$1 \mathrm{Nu}$, Nuca & $1 \mathrm{Nu}, \mathrm{No}, \mathrm{Ni}$ \\
$2 \mathrm{~A}$ & $2 \mathrm{~A}$ \\
$3 \mathrm{La}$ ó Lu & $3 \mathrm{Lu}$
\end{tabular}

(1) L-Terminación de pluralidad. 
Comparando el Nocten con el Vejoz se deduce que $Y$ y No son los prefijos de $1^{a}$ persona, y que la L encierra una sincopación de Y más L. El Nocten trueca la $a$ en $e$.

Distribuidos en el Vocabulario hallamos los siguientes:

$$
1^{\text {a }}
$$

$\begin{array}{lll}\text { Nocatag, Nocay } & \text { - Mío. Pl } & \text { Nocayguet } \\ \text { Ycaobo } & \text { - Mío. } & \text { Nemil } \\ \text { Yaan } & \text { - A mí. } & \\ \text { Ycaiguet nuestro y } & \text { - Mio. } & \text { Tatag }\end{array}$

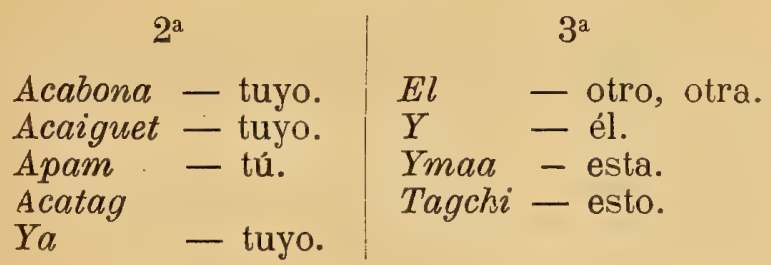

\section{Indefinidos}

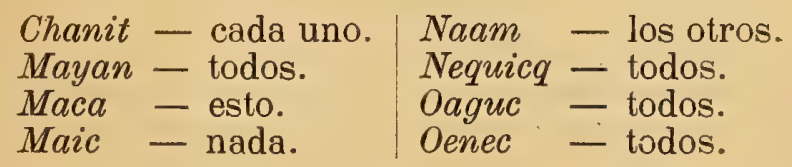

$$
-\S \text { K. - }
$$

\section{Los Numerales}

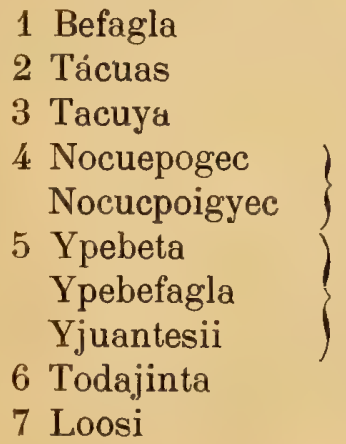

8 Najaela

9 Naya

10 Lagelapleza

11 Yjuantesii

12 Natujuayael

13 Yacpe

14 Alocon

15 Naya

16 Opon

17 Loos 
[ El Mataco, Nocten y Vejoz parece que se valen de diferentes combinaciones para expresar sus numerales.

El Dos es Nitacues en Nocten y Jotejuassi en Mataco, y aquí se acaban las semejanzas. La razón de estas diferencias está en el sentidø etimológico de los temas. Ed. ]

\section{$-\S$ L. - \\ Del Verbo}

[ Sólo se encuentran en el MS fragmentos de conjugación v. gr.
Chijoje Asthia? - ¿ Dónde está tu padre (ha ido).

En el Voc. Ys-quia-padre, sin duda-mi padre.

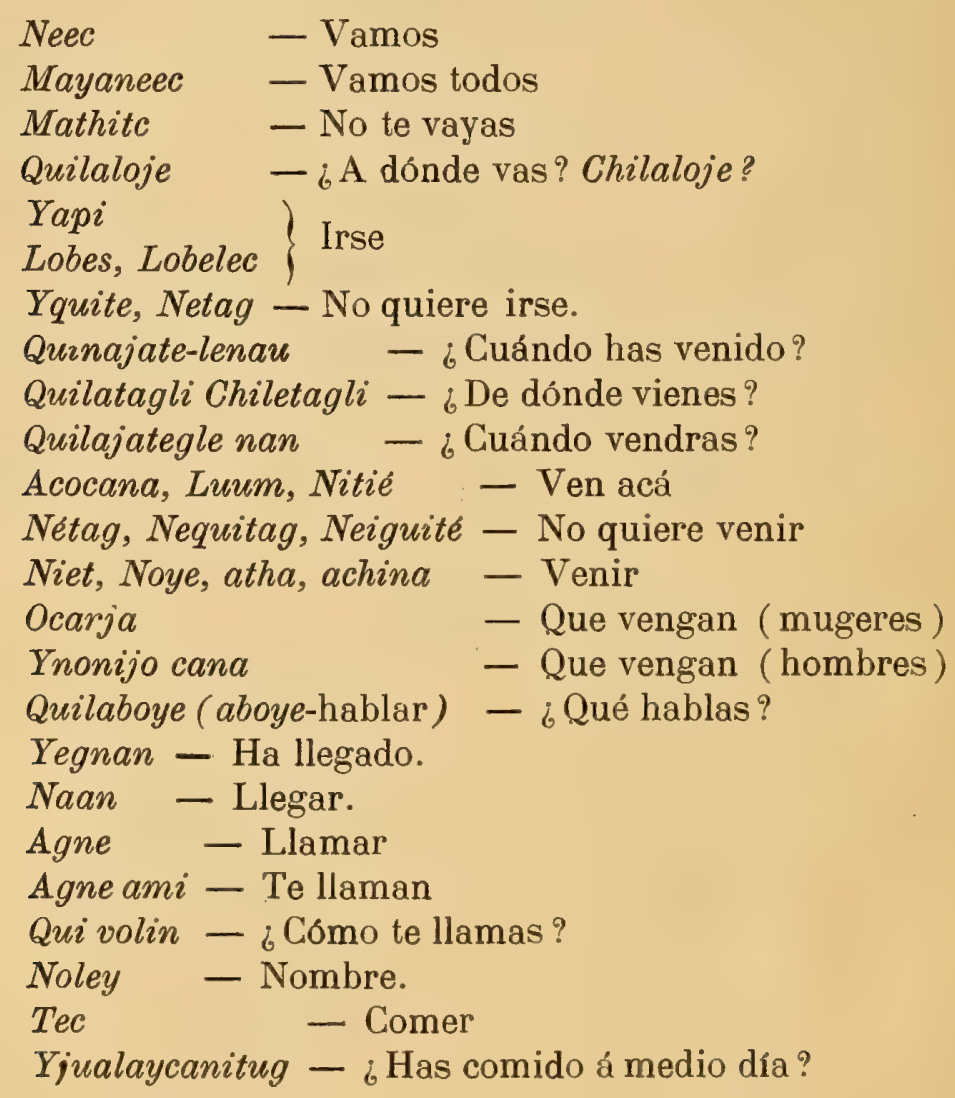




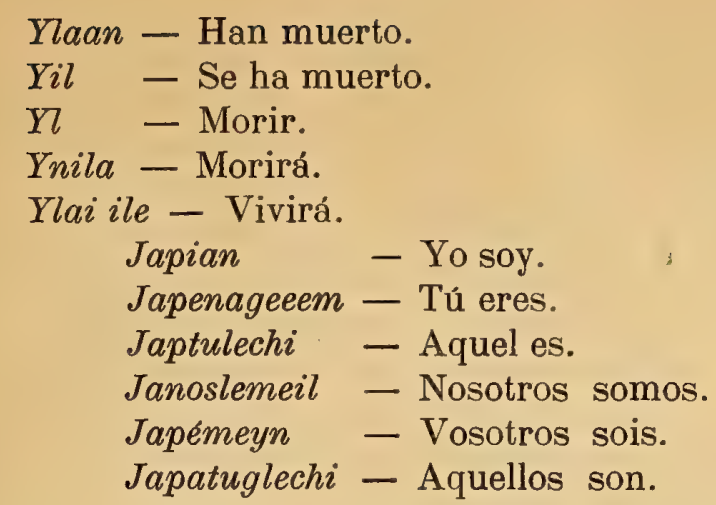

Nota-Compárese el verbo hapini del Quichúa, que en la Argentina se usa para decir-tener ó sea-est mihi $=c^{\prime}$ est á moi.

Con datos tan insuficientes sería inútil la pretensión de querer restaurar todos los giros de la flección Vejosa; pero por suerte los apuntes del P. Inocencio Massei sobre el Nocten nos dan un norte: En ambos dialectos encontramos los prefijos $\mathrm{N}$ y Y de $1^{\text {a }}$ persona y el subfijo le de futuro.

En el Nocten los prefijos verbales serían:

$$
\begin{aligned}
& \text { Singular Plural } \\
& 1 \text { No } 1 \text { Ye-vel Ne-(incl.) } \\
& 2 \mathrm{Le} \quad 1 \mathrm{No}-\quad \text { (excl.) } \\
& 3 \mathrm{Y} \text {-(ó nada) } 2 \mathrm{Le}-\mathrm{i} \\
& 3 \text { Nada ó Y }
\end{aligned}
$$

\section{$\S 1^{\mathrm{a}}$ PERSONA}

De estos prefijos hallamos el No de $1^{a}$ passim ex. gr. Nocagslin-consolar.

Ed. ]

$$
\text { [ } \$ \quad 2^{\mathrm{a}} \text { PERSONA }
$$

Ahora sabemos que la $\boldsymbol{e}$ del Nocten suele reaparecer como $a$ en el Vejoz, desde luego el prefijo Le de $2^{a}$ persona debería sonar como La. Ex. gr. Chijoje Asthia ? Dónde está ó ha ido tu padre?

Chilajoje? - ¿A dónde vas? 
Este ejemplo sería mucho más satisfactorio si no se cruzase de por medio este otro:

\section{¿ Yjualaycanitug? ¿ Has comido á medio día?}

En esta frase la partícula la es orgánica del tema Yjuala.

Quivajate lenau? ¿Cuándo has venido? Chiletagli? ¿De dónde vienes? parece que apuntan en dirección del le Nocten, y si se quiere hacen sospechar que pueda ocuparse también como subfijo.

El mejor ejemplo de $2^{\mathrm{a}}$ persona es:-Quilaboye- ¿qué hablas? —que se descompone así:-Qui-qué-; le-tu-; aboye-hablas.

\section{$\S 3^{\text {a }}$ PERSONA}

Del prefijo Y de $3^{a}$ pueden citarse Yapi-irse-; Yegnan-ha llegado-como ejemplos.

EI P. Remedi nos cuenta que muchos de estos Indios hablan con incorrección, lo que explica muchas deficiencias.

Del $l e$ de futuro es un buen ejemplo:

Quilajategle nan? - ¿Cuando vendras?

Ed. ]

$$
-\S \text { M. - }
$$

\section{Adverbios, Preposiciones, etc.}

Acocana-ven acá.

Achagquie - otra vez.

Aguay-ahi.

Anchajui-adentro.

Ama-no.

Aponag agi-antes de ayer.

Atagnan-poco á poco.

$\mathrm{Ca}$-(prefijo), Ama-no.

Caana-aquí.

Caapa-arriba.

Cagguian-abajo.

Catha-abajo.

Chi (prefijo)- ¿Dónde?

Ynachi-ahí está.
Ynchajui-adentro.

Yninucucchi-por allí.

Ynucuecho-adonde quiera.

Jumien-contra.

Lac (subfijo)-para.

Nachi-allí.

Nite (subfijo)-no.

Puulé-arriba.

Qui- ¿̇Dónde, cuándo, como, qué? se subfija.

Quiiñac-¿qué más?

Tajuajatana $\rightarrow$ ahora.

Yolejatc-atras.

Ziquiac-porqué. 
Nota-Véase mi "Arte Mocoví) pp CGVI et seg. También LII á LIV. Allí se verá el valor interrogante del prefijo $Q=K$ etc. Esta lista presenta temas tentadores para etimologías muy bonitas, ex. gr. Acocana del Toba. Ac-ven-y el adverbio Vejoso cax$n a$-aquí-que incluye los sonidos $K$, preposición y ena, pronombre demostrativo, tan conocidos en los dialectos Mocoví-Guaycurúes. Este estudio empero es sugestivo, y por ahora al ménos cada uno sacará para sí las derivaciones que el oído le sugiera. Ed.]

\section{Conclusión}

Muy sensible es que los apuntes del MS conservado por A. d'Orbigny no sean más explícitos en cuanto al mecanismo verbal del Vejoz; y tanto más cuanto que ni el Padre Remedi, ni el viajero Pelleschi, tampoco dan el paradigma completo de la conjugación de los verbos. El último expresa terminantemente que sus datos eran incompletos; pero hasta donde alcanzan son interesantes y de importancia. Se puede decir pues que por ahora solo contamos con los apuntes del P. Massei para conocer el mecanismo completo del verbo Mataco en general, pero de él se puede deducir lo que será en los demás codialectos.

Por suerte los Vejoses son Indios que aún existen, así que será posible complementar lo que aquí se dá á luz. En fin lo que se publica ahora basta para dar á conocer lo que son estos idiomas del grupo Mataco.

En los capítulos anteriores se ha hecho notar que el Vejoz, el Lengua, el Payaguá y el Guaycurú tienen algo bastante en comùn. De que con el Toba y demás codialectos, se nota la misma tenden. cia á unirse puede demostrarse con las siguientes séries pronominales:

$\begin{array}{lcl}\text { Vejoz } & & \text { Toba } \\ 1 \text { Yaan } & \text { Yo } & \text { Ayin } \\ 2 \text { Aam } & \text { Tú } & \text { Ahan }\end{array}$

\section{Posesivos}

$\begin{array}{ll}1 \mathrm{Ya} \text { o } \mathrm{Y} & 1 \mathrm{Y}, \mathrm{Ya} \text { etc. } \\ 2 \mathrm{~A} & 2 \mathrm{~A}, \mathrm{Au} \text { etc. } \\ 3 \mathrm{La} \text { L } & 3 \mathrm{La} \text { o L }\end{array}$




\section{Todos prefijos}

No cabe duda que estos pronombres y partículas pronominales se derivan de un solo orígen.

Así como en esta parte la semejanza se impone, las omofonias no se reproducen en lo demás del vocabulario, como se podrá ver de esta serie.

\begin{tabular}{|c|c|c|c|}
\hline & Vejoz. & Castellano & Toba (Barcena) \\
\hline & Litec & Cabeza & Colcoic. \\
\hline & Nouse & $B a r b a$ & Yolagayé. \\
\hline & Le-Paset & Barbas & " \\
\hline & Noche & Barriga & Cadaham. \\
\hline & Notoque & Pecho & Yohoge. \\
\hline & Nopane & Cuello & Yocolá. \\
\hline Kaj (R) & Nolagi & Boca & Codap. \\
\hline & Lepujus & Bofes & Lathi. \\
\hline & Nohui & Brazo & Yapigé. \\
\hline & $\begin{array}{l}\text { Juapo } \\
\text { Nolile }\end{array}$ & Canilla & Cadihipirech. \\
\hline & Nocáto & & \\
\hline & Nocachite & $C 乞 d o$ & \\
\hline & Notogtle & Corazón & Quiriacaté. \\
\hline & Noisiglile & Costillas & Canitissit. \\
\hline & Logueg & Ano & \\
\hline & Nojug & Dedo & Cotiagantá. \\
\hline & Nochote & Dientes & Cadové. \\
\hline & Notachio & Frente & Canepé. \\
\hline & Nopagni ) & Cuello & Yocolá. \\
\hline & Nocachi $\}$ & Garguero & Cadacoicquiti. \\
\hline & Litc & Hueso & Pîhinech. \\
\hline & Nopaset & Labios & Canasipissí. \\
\hline & Notel & Lágrimas & Hithí. \\
\hline Haj-le-chá (R) & Nocagliguiu & Lengua & Calatiagath. \\
\hline Cuei (R) & Noguei & Mano & Yuvat. \\
\hline & Nochancat & ,, derecha & Lahí. \\
\hline & Nojoncat & ,, izquierda & Emách. \\
\hline & Nolequic.ó Lêche & Muslo & Cadoteltá. \\
\hline & Nucuebo & Muñeca & \\
\hline & Nonus & Narices & Cadimich. \\
\hline & Loguegchalos & Nalgas & Cadosapí. \\
\hline
\end{tabular}




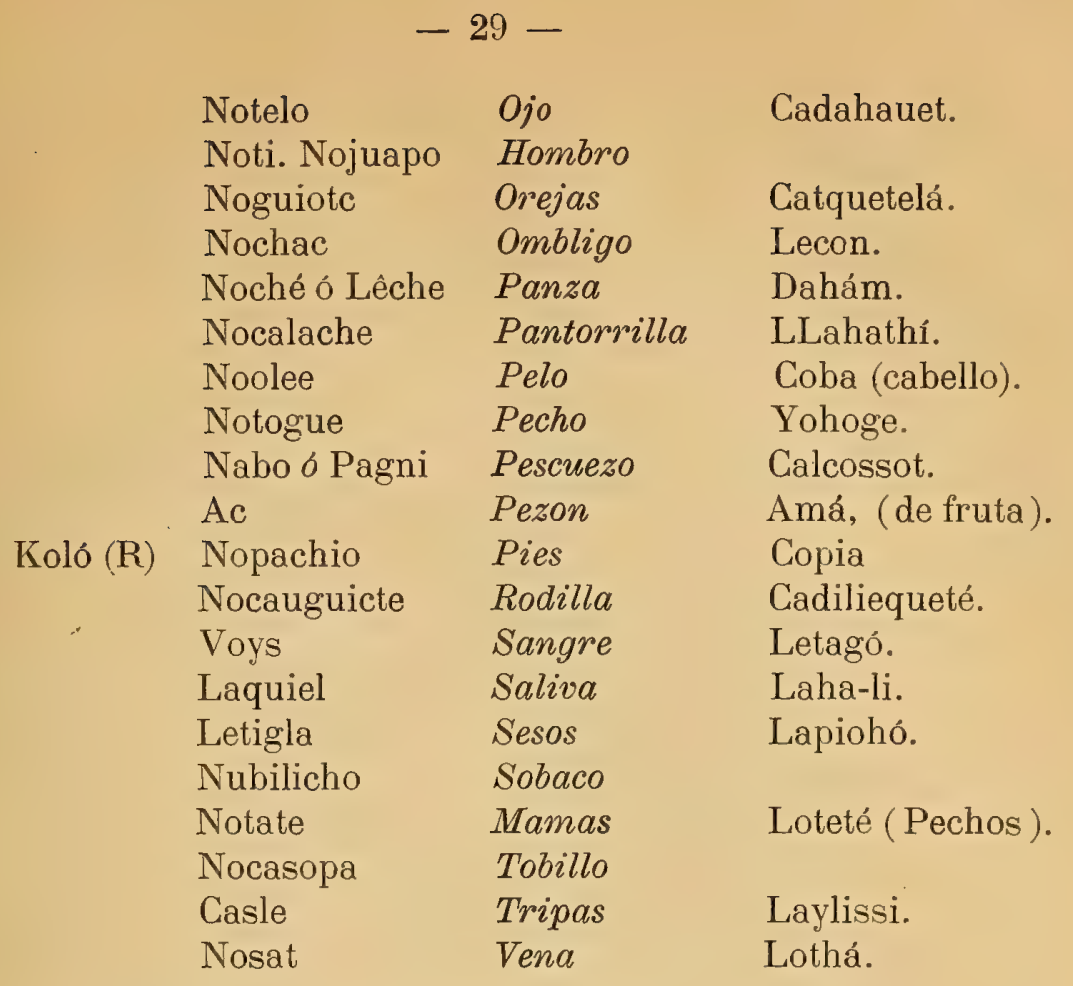

Las analogías entre estas dos listas son bien escasas y aún así dependen de equivalencias fonéticas que por cierto no se ha pretendido dar por probadas; sin embargo en un cotejo con el Mataco de Remedi se ve que este idioma como los demás del Chaco, sea por el motivo que se fuese, cambia los nombres de las cosas.

No se puede desconocer la interrelación que existe entre el grupo Mataco-Mataguayo y el otro de tipo Guaycurú; al mismo tiempo hay que confesar que en sus vocabularios existen elementos que acusan diferencias radicales de aboleng.) étnico-lingüístico. Todo esto nos enseña que en la raza Mataco-Mataguaya tenemos el resultado de hordas Guaycurúes que se impusieron sobre otras de orígen Tonocoté ó Mataco-Mataguayo, dándoles su mecanismo gramatical y adoptándoles su caudal de voces en general.

De aquí se deduce este corolario; las diferencias que advertimos en los idiomas de las diferentes naciones del grupo Guaycurú responden á las mezclas con las varias tribus con que emparentaron cuando se enseñorearon del Chaco. 
Pbeo á poco se irá construyendo el Vocabulario Poligıota de toda esta región, y estoy seguro que con este estudio, puramente mecánico como lo es, se hará la luz donde hoy todo es confusión, y se establecerá este cánon de lingüística argentina: Las Lenguas Argentinas deben clasificarse en primer lugar por su articulación pronominal.

Es para mi un misterio como el grupo de lenguas MatacoMataguayas haya podido permanecer tanto tiempo desconocido por los americanistas. Aún hoy las tribus que las hablan son numerosísimas y más susceptibles de adoptar la civilización europea que otras más rebeldeșá estas influencias, y que esto no obstante figuran en el Catálogo de las Lenguas.

Estas consideraciones son causa que se dé lugar tan preferente á noticias tan escasas como las que ahora se ofrecen en este Boletín; pero la necesidad de conocer algo sobre estos Indios y su idioma se imponía. Apuntes enterrados en las efímeras publicaciones de las Provincias ó en obras extranjeras se escapan á los Americanistas del Mundo Viejo, y son caviare para los aficionados á estas cosas en el nuestro. Como me decía el Señor Lucien Adam en unas de sus cartas; es tan difícil poder procurar lo que se publica en América sobre lenguas indígenas!

En fin poco á puco iremos conociendo las riquezas de lingüística que el territorio de la Argentina abraza en su perímetro, y espero que no se cerrará este siglo sin que tengamos la pista siquiera de todos sus veneros. 


\section{VOCABULARIO VEJOZ CASTELLANO}

IA

$\mathbf{n - A}$, sombra.

Aag, tocar. Ver Calagay.

Aam, tú, japeen.

n-Aam, los otros.

n-Aay, nadar. Ver Nonaig.

n-Abo, flor, pescuezo. Ver Nobotes.

Abocoy, pescar con red.

Aboye, hablar.

Abúchag, chancho.

Abutc loy, caballo ensillado.

Abuté, andar á caballo.

Ac, pezón.

Aca, escremento. Ver Ramuc. [Voz Quichua Ed.]

Acabona, tuyo.

Acaiguet, Acatag, tuyo. Ver Ya.

Acatag, tuyo.

Acateg, agarrar.

Acacona, ven acá. Ver Luum, Nitié.

Aconez, dulce. Ver Acag.

n-Achacaj. Ver Amis.

Achag, pl. Achetas, limón.

Achag, traer. Ver Chag.

Achag-quie, otra vez.

Achagguic, volver á repetir.

Achagle, Ybolejaye, comprar. No cachaja.

Achetatas, sidras.

n-Aches, muchacios.

Achetag, pl. Achetas, naranja.

Achicayguet? cuyo es esto?

Achilac-tage? cuya es esta comida? Pedro lac, de Pedro.

Achimayeg? qué es lo qué?

Achina, venir. Ver Noye.

Achinag chitagchi, quien es ese.

Achine tag?, Achitagge? de quién es eso?

Achinic, el menor.

Achipi, achitape? quién es ese?

Achitagchi? quién?

Achitaglechi? quién es aquel?

Achitag-pa? quién es esta trae ?

Achium, adelantarse.
Achochan, concebir.

Achumagchi? qué es eso? Ver Quiapajate.

Achum, verde.

Ag, cuero.

n-Agguiuyaja, parco.

Agla, sebo.

Agne, llamar.

Agne ami, te llaman

Agpe, grasa.

Agtigquie, alentar.

Agtuc, peer.

Agua, por al fuego.

Aguay, ahi.

n-Aguai, hervir.

n-Aguai-nite, no hervir.

Ahochan, 1, chohochan, estar preñada.

Aiacachis-alta, apartarse.

Aigi, poner en algun lugar. Ver Tinacachi.

Aimpa, arremangarse.

Ain, 3 Aama, arrimar.

Aintacuy, tijera.

a-Aiñac, tus parientes.

Aytag, pl. Aytas, dolor.

Aytag, doler.

Aitas, tasiglin, castigar.

Aitas idlin, azotar.

Aytasalam, enfermar. Ver Tuug.

Aytc, atar.

A jaat, muerto ó difunto. Ver Ilneen.

Ajas, Yas, rocio.

Ajas, raspar, barrer.

Ajat, pl. Ajatas, alma.

Ajatag, diablo. Ver Guac-lauc.

Ajatag, soldado chistiano.

Ajayag, mistol.

Ajec, desollar, Sevil.

Ajoye, achum, adelante.

Ajoye, poner adelante. Ver Majoye y Letagiig.

n-Ajucl, navaja.

Ajuchag, carancho.

A juetes, mojarras.

A juit, 
Ajuminitage, querer. Ver Jumin é Ijumin.

n-A juscocho, nudos de los dedos.

n-A jut, podrido.

A juthi, soplar.

Ajuyeg, consolar. Ver Nocagslin.

Ale-anne-negi, anegi, buenos dias compañero.

Ala jonagnoig, is jonachi, buenas noches compañero.

Alechag, alazan, rubio.

Aleés, tuyos.

Aloblitag, suspirar. Ver Leyalebompa.

Alocon, catorce, 14.

Alotag, pampa.

Aloxa, maduro. Ver Tepeigino y Tepeinitc.

Aloxa, presto. Ver Guatana y Caile.

Aluche, iguana,

Alutag, yacaré.

Ama, no. Ver Ca.

Amalag, 2 Notacagag, guapo.

Amat, ratón.

Ambre, tener.

Amey, vosotros. Yehi.

Amis, 2, Lamis, 1 Nachacaj, gualcas.

Amme, acercarse.

Amotag, pl. Amotas, enfermedad venerea.

$\mathbf{n}-\mathbf{A} \mathbf{n}$, volver, ó venir, adonde se sale. Ver Tepil.

Anal, pl. Analeys, Mataco.

Analatag, nutria.

Anchaglin, 1, Guetlanflin, mentira.

Anchaglin, 1, Yanflin, mentir. Ver Nositabo.

Anchaguinp, meter adentro, ó llevar adentro.

Anchajui, adentro.

Aneg, llenar. Ver Ontepoyeg.

Anictag, porotos.

Aniotag, zapallu negro.

Anlag, vivoras.

Anlin, aullar.

Antac, vrundel.

Antena, buenos dias.

Antonio-lac, para Antonio.

Añat, Anguila.

Apam, tú.

n-Apan, tropezar.

Aponag-agi, antes de ayer. Yer Yonag el nagi.

n-Aponte, zepo.

Aptit, apretar.

Aputag, gobernador. (Voz Quichua Ed.)

a-Asa, hijito tuyo.
Ascan, pato negro.

Asconlùu, amontonar.

Asec, acocear.

Asei, cocear.

Aset, barro.

Aset, plato. Ver Chapel.

Asla, pedir. Ver Nosila y Notala.

Aspe, Aso, pisar.

Asquia-Noig, andar á pié.

Asus, murciẻlago.

Atac, pl. Atas, mosca.

Atachi, esto. Ver Tagchi y Maca.

Atagdchi, ese ó aquel.

Atagle-chaag, qué traes?

Atagnan, Atagnanflin, poco á poco.

Ataguac, empacharse.

Atajuac, empachado.

Atalechi, del otro.

Atasin, menear. Ver Choglin.

n-Ate, pl. Nateles, viudo.

n-Atel, quitataco.

Atha, venir. Ver Niet.

Athila, tu hermano.

Atnjuac, regoldar. Ver Nopat.

Avendaño, dar. Ver Tis.

Aznan, ciego. Vex Ténuc.

Befagla, uno.

no-Belec, lechiguana.

Bochotag, porongo.

no-Botes, pescuezo. Ver Pagni.

\section{$\mathbf{C}$}

Ca, 1, Ama, no. Ytal. $K a$.

Caana, aquí.

Caapa, arriba. Ver Puule.

Cab cayno, no apretado.

no-Cabona, golro. sombrero.

no-Cabotag, 1, Chidaguiltag, lazo.

no-Cachati, suegro.

no-Cachétag, cincha.

no-Cachi, colo garguero. Ver Nopagni.

Cachia, Site, fiera cosa. Ver Site.

Cachia, 1, Sitc, 1, Nisia, malo.

no-Cachien, estornudar.

Cachitag, moral. Ver Yinag y Lacuc.

Cachitag, paloma.

no-Cachite, codo.

no-Cachutc, orcon.

Cagcagno, afolar. Ver Cagcaino (jasolear ó asolar?)

Cagcaino, afolar (sic). Ver Caig juieno.

Cagguian, Catha, abajo.

no-Caglien, mojarse. 
no-Cagliguiu, lengua.

Caglin, caylin, alegre.

Caglin, alegrarse.

no-Cagni, petaca, bolsa.

no-Cagnis, alforjas.

Cagquia, clavar. Ver Thinenthia.

no-Cagquiesag, bostezar.

no-Cagslin, consolar.

no-Caguialtag, mocos.

no-Caguiectag quia, pañuelo.

Cay, pl. Caigies, suyo (cuando la cosat no es viviente). Ver La, pl. Lay.

Caig juieno, Cagcagno, afolar. Ver Gagcaino.

no-Caigies, ajuar.

no-Caiguet, nuestro.

no-Cayguet. Ver Nemil.

Caila, cabra.

Caile, aorita. Ver Guatana.

Cayle-ezlin, apurar á alguna.

Caile, maa, correr.

Caile, presto. Ver Guatana.

Caile laame, vuelve presto.

Cainacasquie, acostar'se.

Cainogia, sonsera.

no-Cainom, peones. Ver Nuchumeniec. no-Caítaglac, yesquero.

no-Cajapotes, mediar.

Cajuel, doblar la ropa.

no-Cajuti, honda.

no-Cala, pata.

no-Cala, bastón. Ver La.

no-Calache, pantorrilla.

no-Calág, cuñado.

Calagay, tocar. Ver Aag.

Calapojo, Calavac, cojo.

Calatu, nubes. Ver Pulc.

Calavac, cojo.

Camag noistag, buenas noches.

Camag, Agnis, lapag, despues.

Camaiscat, no quitar.

no-Camguia, dormir. Ver Yma y Lemma.

Cáneg, guardar.

no-Canguicte, rodilla.

no-Canguiete nenchi, doblar las rodillas.

Canquia, abajo. Ver Gagguian.

no-Canquicte-chinen, arrodillarse.

Canu, abuja, (aguja).

Canujuiis,

no-Cañiacu, paja.

Capuchan, nacer (gente, animai).

Capuchan, parir. Ver Puu.

Caquietag, Cachia, fiero. Ver Cachia.

no-Cás, semilla. Ver Nocaslooy.

no-Cas, chacara. Ver Cashoct, p. Gashoctes.
Cashoct, pl, Cashoctes, chacara. VerNocas.

Casia-nola, mal hombre.

Cásit, pararse, ó estar en pie.

Casle, tripas.

no-Caslooy, semilla. Ver Looy.

Casoini, batir.

no-Casopa, tobillo.

Castac, armado pescado.

Cataatu, granizo.

no-Catag, Nocay, mio. Ver Ycayguet.

no-Catagi, mio.

no-Catagitc, ageno.

no-Catay, voy á cocinar.

Catés, estrella.

no-Cathia, caliente (remedio) .

no-Cáto, codo.

no-Cátog, cuñada.

Catucuetag, bayo.

Catula, dorado.

Catulag, amarillo.

no-Cayaan. Ver Chag.

no-Cayuquie, coton. (algodon).

Caschun, cantar.

Ciatagategle-lec? cuándo te vas? Ver Chiategelapi.

nc-Cluuc, petaca. Ver Nocagni.

no-Cochoim, nudos.

Cochoinuec, alargar.

Coige, jugar.

Cojuc, coujua, regoldar. Ver Nopat.

Colque, plata.

no-Cuc ojuata, pulvera.

no-Cucbo, muñeca.

no-Cuccho, palma de la mano.

no-Cucpoigyec, quatro.

no-Cueche, morcillos de los brazos.

no-Cuenez, macana.

no-Cuepogec, cuatro.

\section{Ch}

no-Cha, chupar.

no-Chac, ombligo.

Chache Cachia, 1, Sitc, 1, Nisia, malo.

Chachos, ubre.

Chag, traer. Ver Achag.

Cha, no cayaan, ganar.

Chagquic, tordillo.

Chagu, calíente. Remedio Nocathia.

Chai, Ierramar.

Chaigue, echar tierra ó tapar el abujero. Ver Pogquie.

Chaipe, guag, Noeteya 2 tathia, bautizar.

Chajatec? quanto? 
Chalag, 1, chalagita, negro.

no-Chaloslie, quijadas.

no-Chancat, derecho.

Chanchiles, Chawe, las partes. (rr .e)

Changuia, derramarse.

Chanit, cada uno. Ver Noveg-yaba.

Chano, chaipe, hechar ó poner.

Chapel, plato. Ver Aset.

Chati, abuelo.

Chatitagilam, cámaras de sangre.

Chazchuc, bailar.

no-Che, barriga.

no-Ché, 1, Leche, panza.

no-Chec, che, coser.

Chec, ver no-Chec.

Cheec, remendar Ver Toy.

Cheón, mandar.

no-Cheg-nacates, hilo.

Cheguoo, pl, Cheguos, cuervo.

Choinat, sabalo.

Chejua, marido ó mujer. Ver Lechejuac.

Chela, esquina.

Cheleg, negro.

Chenlac-chile, palo, borracho.

Chessag, romper. Ver Queisag.

Chetag, barrigón.

Chiasma, rascarse.

Chiategelapi? quándo te vas? Ver Ciatagategle-lec.

Chidaguiltag, lazo. Ver Nocabotag.

Chieel? qué más?

Chiguitag, Chiutag, vieja, pescado.

Chiguititas, plumar. Ver Lejuya.

Chijoje asthia, donde está tu padre (ha ido.)

Chijuic, manantial. Ver Junet.

Chilajoje?, adónde vas? Ver Quilajoje.

Chiletagli?, de dónde vicnes? Ver Quilatagli.

Chinen, Ver Nocanquicte.

Chingilanno, calor.

Chiojocsac, tela de araña.

Chipil, dentera.

Chipup, paloma chiquita.

Chiquita, concha. Ver Lenquictag. no-Chita, tu hermana.

Chiug, Chuugaitag, sudor. Ver Tacagli.

Chiumien, convidar. Ver Huewo, Tisla yjuala.

Chiunpa, comenzar. Ver Telapan.

Chiut, viejo.

Chiutagquic, Chiutagchic, viruelas.

Cho (nonus Cho, l, Nonus choguiag, ñato.

Choc, tener de alguna cosa.
Chocoo, ahogar del pescuezo.

Chocoz, mariposa.

Chochones, matos.

Chodnet, cuchillo.

Choglin, menear. Ver Atasin.

Chognag, Chogneteg, mezquino.

Choguegguie gognet, pisar ó apretar la tierra.

Chogleglin, torcido.

Chohochan, estar preñada. Ver Ahochan.

Chojantieg, prestar. Ver Noguiejaneg.

Chojuac, moler. Ver Quionguan.

Chojueg, abujero (agujero).

Choneglin, pesado ó no ligero.

Chonetag, oveja.

Chonig, peine.

Chopo, rabon.

Chol satoma, Pana, voladora langosta. Ver Pana.

Chota, ayudar. Ver Quiota.

no-Chote, pl, Nochotes, dientes.

no-Chote sanis, encias.

Chototoio, sordo.

Chovalia, olvidar. Ver Nopetula.

Chowe, cazuela. ( $r$ ? )

no-Chug-eleg, abrazar.

Chujuc lámig, chujuclec=acueg, cruzar los brazos.

Chujuenlin, enseñar.

Chulu, paloma del campo.

Chuma, tomar. Ver Choc.

no-Chumienec, peones.

Chumina, alcanzar lo caido. Ver Jumin.

Chunglin, trabajar.

no-Chuñct, arrojar, vomitar.

no-Chuñet, vomitar.

Chupinguia, derecho.

Chuti, cigarro.

Chuugaitag, Ver Chiug.

Chugu, hambre.

\section{$\mathbf{E}$}

n-Eec, vamos; mayanere, todos vamos.

Eel, segundo.

Eeltaxe, tercero.

Eenlin, componer. Ver Yelin.

n-Egelan, tener sed. Ver Ychin.

n-Egéti, sueño.

Eguie, floxo. Ver Notacaxinite.

n-Eipa, colgar. Ver Tecapa.

n-Ejipate 2 Siichet 3 Leche, Ybuct lanflin, contradecir.

El, otro, otra.

Elel chauet, charquear. Ver Novocharqui. 
Eley, tu tio.

n-Emil, nuestro. Ver Ycayśuet. Enlilalin, los reñidos.

Enlin, hacer.

Enlin tatag, ensillar.

n-Epa-madrugar. Ver Lelentag.

Epélatag. Ver Nupa: lalag, Ynupe.

Esguieili, reir.

Esguin, pl. esquinas, zapallo.

Estajuctag, pava del monte.

n-Etag

n-Equita $\}$ no querer venir.

n-Eiguité

n-Etag, Ver Yquite.

Etanchag, ladrón. Ver Ycatan. Etetoitag, pl. Etetoitas, hacha. Eyab, Arecar, abil. Ver Ocoz.

\section{F}

Fana, (así), chiquito.

\section{G}

Gichuc, cagita.

no-Glacue, chifles.

no-Glati, vaso.

Gognet, arar tierra. Ver Osaji.

Gonet, cabar. Ver Yuagi gotnet. no-Gomné, adobe.

no-Gtlin, tener sed.

Guachan, verde yerloa ó planta.

Guachun, babas.

Guag, agua.

Guag-cayo, agua caliente.

Guag-jochi, gochi, agua fria.

Guag-naig, acequia. Ver Nolechenec.

Guag-nolc, bagre.

Guajadlin, ligero.

Gualac lauc, diablo. Ver Ajatag.

Gualaup, tases.

Guanlac, avestruz.

Guanlag, Toba.

Guas eta, boca. Ver Ysan.

Guase, ciervo.

Guaseta, carne. Ver Ysam.

Guatana, presto. Ver Caile, aloxa, aorita.

Guatog, pacara.

Guc, remolino. Ver Saiontag.

no-Guci, mano.

Guiela, luna. Ytal iguelách.

Guela tac poyeg, luna llena.

Guelatal, luna nueva.

Guelas, clara luna.

no-Guen (huit-no guem), regalar.

no-Guen, tener. Ytal nu-hun.
no-Gueno, presentar, dar gratuitamente.

Guesag, gerga.

Guesatag, algodón.

no-Gueti, perderse alguna cosa.

Guetlaflin, mentira. Ver Anchaglin.

Guianis, capar. Ver Nag.

no-Guiejaneg, prestar. Ver Chojantieg.

no-Guinig, hermano. Ver Quila.

no-Guiotc, orejas.

Guiquic, ablandar.

no-Guita, hermana. Ver Quite.

\section{H}

no-Hacla, sobrino.

no-Hag, espantarse. Ver Onochaya.

Hic-lapa, crecer. Ver Talac.

Hichag, anta.

Hijualane, hoy. Ytal. Icualanna.

Hoaytag, pintarse.

no-Huc, tener. Ver Tii.

no-Hueg, huet, silla.

Huonagus, convidar á todos.

Huewo, convidar. Ver Tislá y Juala.

no-Hui, brazo. Ver Juapo.

Huigui, convocar.

Huit geno, dar presentando.

no-Huitac, borlas.

Huya, cuidar. Ver Ycay.

\section{I}

I, él. Ver Y Noon.

no-I, entrar.

Iaaiñac, mis parientes.

n-Iat, capitan.

Ibolechaye, curar. Ver Ylágeg.

Ibolejaye, comprar.

Ibongutla, llover.

Ibolalajaya, pagar.

Ibotia amotag, incordio.

Ibuc, patron.

Ic, si.

Icaobo, mio.

Icaten, ladron. Ver Etanebrig.

Icati, claro. Ver Ysati.

Icay, cuidar. Ver Huya.

Icayguet, nuestro. Ver Nemil.

Icleni, pato chiquito.

Ichato, Yquiat, colorado.

Ichayas, nieto.

no-Ichug-lin 2mo chuglin 3 Nisignée, besar.

Idcachi, allả, no muy lejos.

Idycadni, allá léjos.

Ignat, barro.

Igñat, pared.

Igñatguie, azadon. 
Iguen, 1, noguen, tener. Ytal. nuhunho.

Iguiaya, nieta.

Iguic, acompañar. Ver Moque, Tapuas.

Iguiono, 1, Yguiodlin, sucio.

Ijala pule inquia, dia nublado.

Ijanicte, no suber.

Ijoye, escuchar.

Ijua, amigo. Ver Yojua y Jumenec.

Ijuaba, Yjuala, sol. Ytal. iquala.

Ijuala, luz, mañana. Ytal icuala.

Icuala eb, pasado mañana.

Ijuala nagni, aclararse el tiempo.

Ijualanle, aurora.

Ijualaycanitug?, has comido al medio dia?

Ijuantessi, onze.

Ijuantesi, quinto.

Ijuen, ver'.

Ijuic, seguir á otro. Ver Moquel.

Ijumin, querer. Ver Jumin.

Ijuminite, no querer. Ver Nujunite.

II, morir.

Ilaa, huron.

Ilaan, han muerto.

Ilaan, Laam, matar.

Ilacchin, burlarse. Ver Sumu\%.

Ilảgeg, curar. Ver Tilanan é Ybolechaye.

Iláguic, convalecer. Ver Lagente.

Ilai, ile, vivia

Ileés, mis hijos.

Ilegeg, untar.

Ilen, pintarse. Ver Hoaytag.

Ilejan, continual. Ver Télejan.

Illachi, alli.

Ima, dormir. Ver Nolima.

Imaa, esta.

Imaglegem, atrasarse.

Inacachi, ay está.

Inchajui, adentro. Ver Anchajui.

Inguag, secarse ó cortarse el agua.

Inila, morirá.

Ininucuccho, por alli.

Injuac, viento.

Injuacuetag, mucho viento.

Inoon, pl. Ynolas, indio.

Inoon, hoinbre.

no-Insez guion litec, cortarse el pelo de la corona.

no-Insit notap, cortar hasta la frente.

no-Insiz notasilis, cortar hasta las orejas.

Inucuecho, adonde quiera.

Inupe épelatag, monta á caballo. Ver Nnpa: latag.

Iñat, adobe, adobes hacen. Ver Yenta y Nogomné.
Iñat is, adobera.

Iocachi, allá.

Ip, Yplin, cantar las aves.

n-Ipa, 1, Neguicpa, levantarse.

Ipe befagla, cinco.

Ipebeta, Yjuantesii, cinco.

Iplin, bramar, trueno.

Iquia, ahogarse con agua.

Iquiagquia, caerse. Ver Thiatteen.

Iquien, 2 Silat, 3 Niguayac, chasque.

Iquite-netag, no quiere.

Is, sano, bueno.

Is, aay, 1, aaysay?, están todos buenos?

Is jonachi, buenas noches compañero. Ver Ala jonagnoig.

n-Isa, pl. nisas, zapato.

Isaiia, no bueno.

Isam, carne. Ver Guaseta.

Isan, vaca, Ver Guaseta.

Isati, claro. Ver Sii.

Isato obat -li, liendres.

Isato obatiis, limpiar,

Iscat, etanchag, pl. Icaten, quitar.

Iscat etanchag, robar.

Iscia, muy bueno.

Isquic, Ilano.

n-Isia, enfermo. Ver Yel.

Isia, hermoso. Ver Silentag.

no-Isiglile, costillas.

no-Isigneg, Quici, besar la mano.

Isineg, oler.

Isom, acertar tirando.

Ispet lilé, marlo.

Ispet olec, chala.

Ispetcas, choclos.

Isthia, padre.

Itag, fuego.

Itag moc, ceniza. Ver Micaotag.

Itaguic, eslabon.

Itayeg, picaro

n-Itheet, callar.

Iti, pl. Iti-ctas, azu].

Iui, afiladu. Ver Yuigite, no afilado.

Ivóós, gusanos.

Içquia, Ysquia, padre.

\section{$\mathrm{J}$}

Jacob, p. Lacoo, madre.

Janoslemeil, nosotros somos.

Japatuglechi, aquellos son.

Jape, el otro.

Japeon. Ver Aam.

Japémeyu, vosotros sois.

Japenage eem, tu eres.

Japiam, yo soy. 
Japtulechi, aquel es.

no-Jayenec, yorro.

Jinag, Cachitag, Lacuc, moral.

no-Joet, cama.

Jolejutc, ponerse atras.

Jon, apagarse. Ver Yon.

Jonaachi, noche. Ver Yonaachi.

Jonachi, Vuu, obscuro.

Jonachi ugia, muy obscuro.

no-Joncat, izquierda.

Jopa, cera.

Joquictag, pato blanco.

no-Jouet, lomillos de los indios.

Joytag, calentarse.

Jspet, maiz.

no-Juac, vaho, humear.

no-Juachug, salivar.

Juagi gotnet, cavar.

Juagi, hachear.

Juagquie, rajar.

Juala, dia. Yjualatog, dia claro.

Juan latag, el caballo de Juan.

Tuapo, brazo.

no-Juapo, hombro.

no-Jucl, tener vergüenza.

Juctac, pacu.

Juctigue, hijo de puta.

no-Juec, frente castillo.

Jueguiatag,pl.Jueguitas, garrapata.

Jueguienglin, Juecnacha, engañar.

Juelic, mortero.

no-Jug, pl. Nojus, dedo.

no-Jug loquetag, dedo gordo.

no-Jugi, sortija.

no-Jugni, sortija.

no-Jugtag, pl. Nujustajes, uña.

no-Juguienec, libro.

Jui, afilado.

Juict, afilar.

Juichag, bravo.

Juichanes, chilea.

Juichatas, golondrína.

Juichecyag, rayo.

Juicheөc, nublado.

Juichucue, palmar.

Juichue, palma, árbol.

Juietlami, fajarse.

Juiño, braza.

no-Jumée, echar, arroja de sí.

Jumien, contra, cachi jumin, amar.

Jumin, querer. Ver Yjumin.

Junet, manantial. Ver Ghijuic.

no-Juti, podrirse,

Jutuec, juntos.

no-Jutuec lagni, cerrar la boca. Ver Ognilagni.

no-Jutuec, juntarse.

Juum, lanza.

\section{L}

La, baston. Ver Nocala.

La, leña, palo.

La, pl. Lay, cuando es viviente la c)sa que poseemos, como: perro, caballo, etc., significa-iuyo ó de aquel.

10-La=lac, para el hombre.

La ilameel, acometer.

Laame, vuelve presto.

Laamet, el cuento.

Labag, quemar. Ver Nooyo.

Labo, azar ó flor de los árboles.

Lac, comida. Ver Noslac.

Lacas, tabano.

Lacaucu, rincon.

no-Lacpois, calzones.

no-Lachil, saliva. Ver Laguiel.

no-Lag, sano.

Lagelapleza, diez.

Lagni (Nojutuec Lagni), cerrar la

boca. Ver Ogni lagni.

Lagni, encender. Ver Ugno.

no-Lagni, Nolagi, boca.

no-Lagni, capar.

Laguagua, Yuug, adormecer.

Laeil, asesar.

Lainlele, trampa.

Lajoo, último.

Lamis. Ver Amis.

Lanflin, cargar.

Lapag, crudo.

no-Las, tu hermana.

Lasáag, chiquito.

Lasag, pequeño.

Lat-ag, pala.

no-Latama, entender.

Latales, yerbas.

Latatag, lobo.

Latitá áma, entender.

Latne-ama, 1, lata, oyr.

no-Lauet, mesa.

Lay, tío.

no-Tay, librar ó rescatar á alguno.

Layjas, fruto recien cuajado.

Leche, panza. Ver Noché.

Lecheiel, abortar.

Lechejuac, marido ó mujer.

no-Lechenec, acequia. Ver Guagnaig.

Lechénici, chañar.

Lechi, divieso.

Leey, mi tio.

Leg, pl Lejuis, ala.

no-Leg, 1, Leg, lavar. Ver Lejo.

Legi, baina, forro.

Legueil, saliva. Ver Nolachil. 
Leguias, cola.

no-Leguic, muslo. Ver Léche.

Leine, lengua, idioma.

Leji, corral.

Lejo, 1, Noleg, 1, Leg, labar.

Lejuapo=chag, mango.

Lejuya, plumar. Ver Chiguititas.

Lel, pl. Lelises, caracol.

Lelachugiji, coinparlecerse:

Leles, hijos. Ver Noles.

Leltaje, gualcas amarillas de los indios.

Lemeil, nosotros, Namil.

Lemma, dormir. Ver Nolima.

Lenac, papas del monte.

Lenaca, bejuco.

Lenguic, desgranar.

Leni chianis, capar. Ver Nag guionis.

Leni, sacar.

Leni ijijinitc, no sacar.

Lénig, pl. Lenijua, sobrina.

no-Lenlin, pasear. Ver Obelec.

Lenquictag, concha.

Leñec, concha grande.

Lepaset, Pase, barbas.

Lepes, punta.

Lepujus, bofes:

Lequeilan-aitag, calambre.

Lequies, romper.

no-Les, hijos. Ver Leles.

Lesairdlin, escribir.

Lesug, pl. Lesujuis, cuestr. no-Let, vela.

Letagiig, poner adelante.

Letec, cumbrera.

Leteg, peinarse. Ver Nosit.

Letigla, sesos.

Letoig, rincon.

no-Ley, nombre.

e-Léy, tu tío.

Leyalebompa, suspirar. Ver Alobleitag.

Lichag, pobre.

Lichagjajucim, muy pobre.

Liguiu, huevo.

no-Lile, canilla.

no-Lima, dormir. Ver Lemma.

no-Lini nohuc, desnudarse.

Linsag, pl. Linsas, delgado.

Litc, pl. Licta, huesc.

Litec, cabeza.

Lobes, Lobelec, irse.

Lobuque, casa. Ver Hoet.

Locag, freno.

Logueg, ano.

Logueg chalos, nalgas.

Lompen, flaco.
Loo, el miembro.

Loos, diez y siete, muchos.

Loosi, siete.

Loota, mitad.

Looy, semilla. Ver Nocas.

Lopep, tapon.

Lotag, Loy, caballo. Abutc loy, caballo ensillado.

Lotec, flecha.

Ltunquie, alumbrar.

Lucha, moza.

Luchag Yris Labo, arco. (En el original está puchag).

\section{no-Luglin,}

Lupuc, zenza.

Luum, ven acá.

Luumpa, volar.

\section{$\mathbf{L}$}

LLamuc, basura.

M

Ma, Maapi, vete.

Maa, correr.

Maa, Maa =api, no. Matitc, anda, vele.

Maapi. Ver Ma.

Maca, esto.

Macquia, conejo.

Machita, abispa.

Magse, pl. Magses, Mansi, mozo.

Maic, nada.

Majoye, poner adelante.

Maletuec, darlo todo.

Manteg, basta, dejar.

no-Mapa, cerrar los ojos.

Mateec, andá á comer.

Mathitc, no te vayas.

Meet, verdad.

Ytal, mat, cierto.

Meetite, no verdad.

Ytal, mattitde, falso.

Meinis, alforjas. Ver Nocagnis.

Moquel, seguir á otro. Ver Yjuic.

Motag, afuera.

Muc, alrecho.

\section{N}

no-N=macas, quebrar. Ver Echa.

Na, sombra.

Naam, los otros.

Naan, llegar de alguna parte.

Naay, nadar. Ver Nonaig.

Nabo, flor, pescuezo. Ver Nobote. 
Nachacaj. Ver Amis.

Naches, muchachos.

Nachi, alli.

Nag guianis, capar.

Nagguiuyaja, parco.

Naguai, hervir.

Noguai-nite, no hervir.

no-Nai, Nonaiji, bañarse, nadar.

Naig, camino.

no-Naig, 1, Nonaigi, nadar. Ver Naag.

Najaela, ocho.

Najucl, navaja.

Najuscocho, nudos de los dedos.

Najut, podrido.

Nan, volver, ó venir adonde se sale Ver Tepil.

Nanitag, agua salada.

Napan, tropezar.

Naponte, cepo.

Nasuc, papas.

Nate, pl. Nateles, viudo.

Natel, quitataco.

Natujuaya el, doze.

Naya, quinze, nueve.

Neec, vamos; mayaneec todos vamos.

Negelan, tener sed. Ver Ychin.

Negelanpillan, tener sed. Ver Nogtlin.

Negéti, sueño.

Neguiachic, nuevo.

Noipa, colgar. Ver Tecapa.

Nejipate, 2 Sichet, 3 Lech, Ybuct lanflin, contradecir.

Nemec, huerfano. Ver Pomag.

Nemil, nuestro. Ver Ycayguet.

Nemitag, 1, Niguianet, de mañana ó muy templano.

Neneyg, altrede.

Nepa, madrugar. Ver Lelentag.

Nequela, primero.

Nequicg, todos.

Nesla, abeja de tierra.

Netag, Ver Yquite.

Nétag

Nequitag no quiere venir.

Neiquité

Nethaec, nuevo.

Niag, Niacu, chaguar, comida uyé.

Niat, capitán.

Nichag, chancho. Ver Satay y Abúchag.

$\left.\begin{array}{l}\text { Niet } \\ \text { Noye }\end{array}\right\}$ venir. Ver Atha.

Nigui noquioya, espesar.

Niguianet, de mañana ó muy temprano.

Niguici, chuña.
Nihilud, talega de chaguar.

Nijaneyec, saber. Ver Yaneg, Taig y Tetag.

Nijuc, dentudo pescado.

Nilag noig, hasta mañana.

Nipa, 1, Neguicpa, levantarse.

Nisa, pl. Nisas, zapato.

Nisia, enfermo, malo. Ver Yel y Chaco.

Nisoy, sul.

Nisua, malo.

Nitheet, callar.

Nitie, ven acá. Ver Luum.

Nocaiguet, nuestlo.

Nocatag, mio.

Nocatagi, mio.

Nocay, mio.

Nola-lac, para el hombre.

y-Nolas, los hombres.

y-Noon, el hombre, del hombre, para el hombre.

Nubilicho, sobaco.

Nucuenaig, caminar.

Nugguic, rempujar. Ver Yomec.

no-Nugquia, bajarse.

Nujunitc, no querer. Ver Yjuminite.

Nujuquienec, papel.

Nupa: latag, Ynupe epélatag, monta á caballo.

Nupa, salír.

Nupa -cupa, subir.

Nupel, sombra.

no-Nus, narices.

no-Nus cho, l, Nenus choguiag, ñatoNuunti, 3 Tuunti, la carga.

\section{(1)}

Oaguc, todos. Ver Nequico.

Obat=li, liendres. Ver Ysato.

Obelec, andar, caminar, Ver Obest Nobeleclin.

Obelec, 1, Obes, pasear. Ver Nolenlin.

Obes, pasear. Ver Obelec.

Obest, andir, caminar.

Oblitag, triste.

Oblitagjite, no triste.

Obtac, lapacho.

Obtiin Obtcheet, callar: calla Quiet Nitheet.

Ocosa, espantar.

Ocosla, arrean.

Ocoz, si arrean.

Odla-ienlin, vestirse.

Oénec, todos. Ver Oaguc.

Oglipe, desgarrar la ropa.

Ogni, cerrar. 
Ogualag; leon.

Oguanag, quirquincho: Ver Teletag.

Ohonohagnietc, no-tener miedo.

Ojuata, pulvera. Ver Nocuc.

Olajaya, pagar. Ver Ybonlalajayá no-Olcc, ojas. Ver Olee.

no-Olci, lana. Ver Yic.

Olec (Togniquiela Olec), desojar.

no-Olee, pelo. Ver Olcc.

Omet, apagar el tuego ó vela. no-On, hombre.

no-On is, hombre bueno.

Onachaya, espantarse. Ver Nohag.

Onohaya, miedo. Ver Noai.

Onohaya-nite, no miedo.

O8, gallo, gallina.

Ope, taparse.

Opou, diez y seis.

Orotag, arena.

Osaji, arar. Ver Gognet.

Osen, cuña.

Otag, asar.

Otama, red.

no. Oteya, 2 tathia, bautizar. Ver Ghiape guag:

Otieni, freir. Ver Túleg.

Oubache, barrer.

Oyenquic, abrir. Qui-gajo; nope, la puerta.

no-Oyo, quemar.

\section{$\mathbf{P}$}

Pacchimente, quando se fué.

Pacquic notudguic, ya sembré.

Pachinquic, trenzar.

no-Pachio, piés.

Pagla, luna menguante.

no-Pagni, l, Nocachi, garguero.

Pagni, pescuezo.

Pagniquieteg, cedro.

Paina, mostrar alguna cosa. Ver Tigigi.

Pale lobucua is, la casa de padre es buena.

Pale la Francisco caigi, ese de e? Padre.

Pana, agil.

Panantag, asi grande.

no-Pane, cuello.

Pápa
Pájiempa sentado.

Pase, barbas. Ver Lepaset.

Pasé, pico de las aves.

no-Paset labios.
no-Pat, regoldar. Ver Atajuac, Cojuc, Coujua.

Pazquie leije, bautizado, ó que tiene nombre.

Pazquie leijijinitc, no bautizado. Ver Leijijite.

no-Pe=ot, puerta.

Pedro cayguet? \& Es de Pedro?

Pedro lac, de Pedro.

Pedro tajelechi ? Es de Pedro esto?

Peelag, blanco.

Pelag, blanco.

Pelagquietag, pl, Pelagquietas, blanco.

no-Pen, Nolac, guisar.

no-Pequiia \} llave.

no-Pethia

no-Petula, olvidar. Ver Ghovalia.

Piin, silvar.

Pilog, hondo.

Pina, mostrar alguna cosa. Ver

Paina Tigigi.

Pinu, miel.

Pitag, largo.

Pogni, raya, pescado. Ver Taajan.

Pogquio, echar tierra ó tapar el abujero. Ver Ghajguc.

Ponag, huérfano. Ver Nemec.

Poncho pelatag, fresada.

no-Ponec-lac, cocinar.

no-Ponec, hilado, mote.

Poperi, palma grande.

Poxo, Poxotas, quebrado.

Poxo, rajarse, quebrarse, rebentar. Ver Sayec.

no-Pu, caja.

Pulc, nubes. Ver Calatu.

Puntag, caxa de tocar.

Puu, parir. Ver Capuchan.

Puule, arriba. Ver Gaapa.

\section{$\mathbf{Q}$}

Quasetacathos, queso.

Queisag, romper. Ver Lequies.

Qui ? De dónde?

Qui, adónde, de donde.

Qui, adverbio á que se arriman otras sílabas cuando se añade á algun verbo. V. g. Quijatiglenann?¿quándo vendrás ó to irás? Ver Yapi.

Qui ininucuec? por dónde?

Qui volin? \& cómo te llamas?

no-Quia = chule, chuqui, chupar.

Quiajate lecjec, cuando va. 
Quiaxati, quanto.

Quiala, lagartija.

Quiapa, lomillos.

Quiapajatc? ¿qué es eso?

Quic, adonde está.

Quicgni, tender.

Quici, besar la mano. Ver Noisigneg.

Quicltagilan, toser.

Quictag, catarro.

Quicyaspa, levantar arriba alguna cosa.

Quiczajiji, abrir la boca.

Quicha? ¿dónde está?

Quicho? ¿ en dónde?

Quieltagilan, estar encatarrado.

Quienas, no llano.

Quiesag, sarna.

Quiet, callar, calla.

Quietajin, aguarda un poco.

Quieto matitc, aguardar. Ver Nipinuquioya.

Quigni, estender.

no-Quiin, tener sed.

Quiiñac? qué más?

Quila, hermano. Ver Noguinig.

Quilaboye, que hablas.

Quilajategle nan, quando vendrás.

Quilajoye? adónde vas? Ver Chilajoye.

Quilatagli? por dónde?, de dónde vienes? Ver Ghiletagli.

Quileis, chinas, fornicar. Ver Tuug.

Quiliguiac, lechuza.

Quin, cuerno.

Quina atoic, quando irá.

Quinag, plato.

Quinagchog-non, anzuelo.

Quinagtelo, cascabel.

Quinagtoin, barreno.

Quinajate-lenan? quándo has venido?

Quineg, $\}$ en dónde ?

Quinsag, poquito.

Quinunucuc, por donde.

Quionguan, moler. Ver Chojuac

Quiota, ayudar. Ver Chota.

Quisajo = nope, abrir la puerta (g?) Quite, hermana. Ver Noguiła.

Quiuncacu, surubi.

Quiuncata, fiar. Ver Tisiapag (?)

Quivoslen? \& cómo se llama?

\section{$\mathbf{R}$}

Ramuc, mierda. Ver Aca.
Sagal, camisa.

Saiontag, remolino. Ver Guc.

Sansameg, hablar en secreto, ó al oydo.

Sapi, colar.

no-Sat, vena.

Satay, chancho. Ver Nichag.

Satona, langosta voladora. Ver Ghoy y Pana.

Setag,

Siteg, suelo.

Seteg, pegarse.

Signag, perro.

Signagvos, pulgas.

Siguiet, sobremesa de chaguar.

Sii, claro. Ver Ycati.

Siichet, Ver Nejipate.

Silacay, gato montés.

Silat, Ver Yquien.

Silentag, 1, Yojuan, lindo.

Sinaj, pl. Sinas, perro.

Siquiat, sacudia.

no-Sit, peinarse. Ver Leteg.

no-Sitabo, mentir. Ver Anchaglin.

Sitc, Ver Cachia.

Site, fiera cosa. Ver Cachia.

no-Slac, comida. Ver Lac.

no-Slacucy, chifles. Ver Noglacue.

no-Slla, pedir. Ver Notala.

Snag guajaliu, perro ligero.

Suguanlocuc, araña.

Sugulac pl. Suguanes, hormiga.

Sujuijo, arrugarse.

Sumuz, bur'ar'se.

Suta-numquie, desigual.

Sunc, Ysuc, pl, Sucuis, sonzo.

Suulag, espero. Ver Notuunti.

Suulag, oso hormiguero.

Suvélac, sandia.

\section{$\mathbf{T}$}

no-Ta, no tener.

Tab pelaglinn.

no-Tacagli, 1 , Nocaglien, mojarse.

TacagIi, 1, chiug, chuugaitad, sudar.

no-Tacajui, trabajador bueno.

no-Tacaxanite, floxo.

no-Tacayag. Ver Amalag.

Tacguiacabona, quitarse el sombrero.

Tácuas, dos.

Tacuya, tres. 
no-Tachio, frente.

Tachoc, cadillo.

Tachucuita, robal, pescado.

no-Taesnates, azotes.

Tag tagchi, aquello. Macha; Jatalechi, aquello.

Tagchi, esto.

Taglele, pl, tagleleis, Mataguayo. no-Taglo, pelear.

Tagloo, chorrear.

Tagna, sapo.

Tagquia, baja lo colgado.

Taig saber. Ver Yaneg, Nija-

Tetag $\}$ neyer.

Tainguia, azuela.

Tajeslechi, aquellos.

Tajuaja-tana, ahora.

Tajueleg, conocer.

Tajueniégte, no conocer.

Tajuyguec, conversar.

no-Tala, pedir. Ver Asla.

Talac, crecer. Ver Hic-lapa.

Talg, nacer (planta).

Tanec, higado.

Tangua, solo.

Tantan, 1, tenten, pan.

Tapuas, acompañar. Ver Iquic y Moque.

Tapuya Padre cainugia, confesarse.

Tasiglin, castigar. Ver Aitas.

Tasloc, zorro. Ver Mau.

Tatag, nuestro (?)

no-Tatajuee, cerro.

no-Tate, tetas.

Tathia, Ver Chaipe guag, bautizar.

Tatho, pl. Tactunes, Vejoso

Tato, espolonear.

Tato, locay.

Tec, comer, comezón tener.

Tecapa, colgar. Ver Neipa.

Tecnhiac, secarse.

Tecta, río.

Tecta ilajucchi, rio caliente.

Tecta ilajucnijuctic, teta $=$-iin, rio manso.

Tectapoig, Tetacuug, río crecids.

Techogtag, muy borracho.

Techuc, morera.

Teglin, llorar.

Tegquicl, chispa.

Teigji, monte.

Teigjua, ahorrar poquito.

Teijitag, monte grande.

no-Tejuaye, tejuaye, casarse, se ha casado.

no-Tela, abuela.

Telag, chucho.

Télajan, Ylejan, continuar.
Telapan, comenzar. Ver Chiunpa.

Teletag, quirquincho. Ver Oguanag.

Teliguiguic, igual.

no-Telo, ojo.

Ténuc, ciego. Ver Aznam.

Tepei, agrio.

Tepeigino, tepeinitc, maduro.

Tepeinite, no agrio.

Tepil, Nan, Tepil-la, volver, ó venir adonde se sale.

Tepoye, lleno.

Tesa, pl. tesales, viuda:

Tesue, arrugas.

no-Tet-ii, lágrimas.

Tetaig, pl. tetaiglin, perderse alguna cosa. Ver Nogueti.

Tetaijua, está ocioso.

Thiatteen, caerse. Ver Yquiagquia. a-Thila, tu hermano.

Thinenthia, clavar. Ver Gagquia.

no-Ti, hombro. Ver Nojuapo.

Tiag, tixar ó disparar alguna cosa.

Tiag-tuug, quemar. Ver Nooyo y Labag.

no-Ticadni, hechar, arrojar de sí.

Tichiel, grillo.

no-Tichium, congojarse.

Tié, hilar.

no-Tiet, luz de la vida.

Tigi, pan.

Tigigi, mostrar alguna cosa. Ver Pina y Paina.

Tiglapa, pesar. Ver Ytitnum.

Tigpe, Tépe, cargar.

Tiguiunquic paam, congojarse. Ver Notichum.

Tilag, acarrear.

Tilaglipeel, volver del otro lado alguna cosa.

Tilanan, curat. Ver Ylageg é Yboleshaye.

Tinacachi, 1, Aigi, poner en algun lugar.

no-Tinic, hermano pequeño.

Tipa cabowa, cubrirse ó ponerse el sombrero.

Tiquiunquie pana nolitag, acordalse de cosas tristes.

Tiquiunque_-liebay, acordarse.

Tis, dar. Ver Avendamo.

(?) Tisiapag, fiar.

Tisla yjuala, convidar.

Tispetu, garuar.

Titihuim, pelear.

Tobcg, olla.

Tobobii, caldo.

Tobocoy, borracho, embolrachalse. 
Todajinta, seis.

Toj (Yjuala Tog), dia claro.

Togne, Toan, tirar de algun a cosa.

Tognela tales, desyerbar.

Tognequiela olec, deshojar. no-Togtle, corazón.

no-Toguc, pecho.

Tojoe, tojoy, léjos.

Tojuiase, hablar á solas.

Tolcag, galápago (tortuga).

no-Tolilé, caja.

no-Tonec, espeso.

Tonlaglin, redando. Ver Letoig.

Toone, estirar bien.

Tooppa, alto.

Toy, remendar. Ver C'heenec.

no-Toyen, Notijo, agujerear, barrenar. no-Tuclin, volver á todos lados, dar vueltas.

Tuchag, 1, Tuchetag, niebla, humo.

Tuchotag, humareda.

no-Tuguic, ya sembré. Ver Pacquic.

no-Tugaz, pedo.

no-Tuglez, chicharron.

Tujuac, empacharse. Ver Ataguac.

Tujuanteiji, quarto.

no-Tujuantés, contar. Ver Yámé.

Túleg, freir. Ver Otiene.

Tupa, Dios.

Tuudguic, sembrar.

Tuug, tujula, quimo, beber.

Tuug, enfermar. Ver Aytasalayn.

Tuug, fornicar. Ver Quileis y Gua-

laiachag.

Tuul, orinar.

Tuum, fuerte ó duro.

Tuunsti, apretado.

Tuunte, piedra.

no-Tuunti, espejo.

Tuupa, Dios.

Tuuwe, duro.

\section{$\mathbf{U}$}

no-Uaela, nieto. Ver Yuiayas.

Ubalais, cosquillas.

n-Ubilicho, sobaco (axila).

Ucag, Lutag, grande (femenino).

n-Ucuenaig, caminar.

no-Uet, cama.

no-Ueteslay, mesa.

n-Ugguic, rempıjar. Ver Yomec.

Ugno, encender.

n-Ujunitc, no.querer. Ver Yjuminite.

n-Ujuquienec, papel.

no-Uletei, botones.

Unsit, cortar.

n-Upa, salir.
n-Upa cupa, subir.

n-Upa: latag. Ynupe epelatag, monta á caballo.

n-Upel, sombra.

Upien, agacharse.

Upun, agotar.

no-Use, barla.

Ut, mango. Ver Lejuapp=chag.

Uttuni, vejiga.

Utuni, calentar algo. Ver Tigi itag.

Utunlin, Utuunlin, Joytag, calentarse.

Uucue, buscar.

n-Uunti, 3 Tuunti, la carga.

Uyé, comida.

no-Vainita, no hay.

no-Vainita, 1, Nota, no tener. Ytal. huenitdé non=ho.

Vasilotc, pedir licencia ó avisar.

no-Veg-yaba, cada uno. Ver Chanit.

Vidgute, vito, uit, meter.

Vocogi, arrojar, vomitar. Ver Nochunet.

no-Vocharqui elel chauet, charquear.

Vosa, abeja.

Vosilam, agusanarse.

Vosochag, negra.

Voys, sangre.

Vup, paja.

Vuu, oscuro. Ver Jonachi ó Yonachi.

Vyeglog, chaguar, fruta.

$\mathbf{Y}$

Ya, tuyo. Ver Acaiguet, Acatag.

Yaan, á mi, jo.

Yacaileg, afligirse.

Yacpe, trece.

Yag-tag, apasanca.

Yag, tigre.

Yagset, pl. Yagsetes, pescado.

no-Yaidni, leer.

Yaigno, asomarse.

Yainpa, abrir los ojos.

no-Yaitlami, fajarse. Ver Juietlami.

Yaja is? estás bueno? Is istat, bueno, hiel, malo.

Yaja, estás (colgado).

Yajasquie, adelgazar.

no-Yalo, carrillo.

Yalcaltag, tragon.

Yámé, contar Ver Notujuantés.

Yamme jamoapian, yo soy.

Yan, huir. 
Yaneg, nijaneyec, saber. Ver Taig. Yanflin, contar, mentir. Ver Anchaglin.

no-Yape, papel. Ver Nujuquienec.

Yapi, ilse, voy. Ver Lobes é Hic.

Yapina, zancudos.

Yas, hijo, rocio. Ver Ajas.

Yasa, hijito mio.

Yase, hija.

Yatag, gordo.

Yatc, tinaja.

no-Ye, venir. Ver Atha.

Yeclag, porongo de abejas.

Yechegla, calambre. Ver Lequeilan-aitag.

Yeg nan? ¿ ha venido?

Yeglin, reñir.

Yel, enfermo. Ver Nisia.

no-Yel, cansado.

Yélin, Eenlin, componer.

Yenguietajes, pelar ó quitar la cáscara.

Yenta, adobes hacen. Ver Yñat.

Yés, cortarse el hilo.

Yesnag, gavilan.

Yetig, camotes.

Yic-lana. Ver Nolei.

Yil, se ha muerto.

Yinag, moral. Ver Jinag.

Yjanicte, no saber.

Yo, cocido.

Yoc, silvar. Ver Piin.

Yoclep, relámuago.

Yocos, 1, yocuas, tabaco.

Yocuag, morder.

Yogle, hipo.

Yojua, amigo. Ver Jumenec.

Yolejutc, atras.

Yomec, rempujar.

Yon, apagarse (el fuego).
Yonaachi, noche.

Yonag, tarde.

Yonag-agi 6 Jognag agi, ayer.

Yonag el nagi, antes de ayer.

Yooc, palo santo.

Yopuley, cielo. Ytal ppe-lé. Ver Pule.

Yopuley, cielo de los bienaventurados.

Yoquictag, pato blanco.

Yotac, barbiquejo.

Yuagi ó Juagi, hachear.

Yuagi (Juagi) gotnet gonet, acabar.

Yuagquie, rajar.

Yuay, algarroba.

Yuayug, Indio viejo.

Yuctac o Juctac, pacu.

Yuctigue, Juctigue, hijo de puta.

Yuéguienglin, Yuecnacha, engañar. Ver Jueguienglin.

Yueguiatag, pl. Yueguiatas, garrapata.

Yuelic, mortero.

Yuiayas, nieto. Ver Nouaela.

Yuichag 6 Juichag, bravo.

Yuichanes ó Juichanes, chilca.

Yuichecyag, rayo.

Yuicheec, nublado.

Yuigité o Yuijutetc, no afilado.

Yuinetés, mosquito. Ver Juinetés. Yuiño ó Juiño, brasa.

Yuletilanno, tener frio.

Yủmeg, tirar ó botar alguna cosa.

Yuug, adormecer. Ver Laguagua.

Yuum, lanza.

$\boldsymbol{Z}$

Ziquiac, por que. 


\section{VOCABULARIO CASTELLANO VEJOZ}

\section{A}

A mi, Yaan.

Abajo, canquía, cagguian, catha.

Abeja, vosa.

Abeja de tierra, nesla.

Abil, eyab-arecar, ocoz.

Abispa, machita.

Ablandar, guicquic.

Abortar, licheiel.

Abuelo, chati.

Abuela, no tela.

Abrazar, nochug-eleg.

Abrir, oyenquic, Quigajo =nope, la puerta.

Abrir los ojos, yaimpa.

Abuja, canu. Ver Aguja.

Abujero, chojueg.

Acarrear, tilag.

Acequia, guagnaig, nolechenec.

Acercarse, amme.

Acertar tirando, ysom.

Aclararse el tiempo, yjuela nagni. Acocear, asec.

Acometer, la ilameel.

Acompañar, iguic, moque, tapuas. Acordarse, tiquiunque liebay.

Acordarse de cosas tristes, tiquiunquie pana nolitag.

Acostarse, cainacasquie.

Acostumbrarse, ajuit, no ajuitninitc

Adelante, agoye, achum.

Adelantarse, achium.

Adelgazar, yajasquie.

Adentro, anchajuí, inchajui.

Adobe, yñat, nogomné.

Adobes hacen, yenta, yñat.

Adónde?

Adonde está, quic.

Adonde, de donde, quí.

Adónde vas? quilajoje, chilajoje?

Adonde quiera, ynucuecho.
Adormecer, laguagua, yuug .

Adrede, neneyg.

Afilado, jui.

no-Afilado, yuigite, yuijutetc.

Afilar, yuict, (juict).

Afigirse, yacaileg.

Afolar, cagcaino, caig juieno, cagcagno.

Afrecho, muc.

Afrentarse, najuel.

Afuera, motag.

Agacharse, upien.

Agarrar, acateg.

Ageno, nocatagite.

Agil, pana.

Agotar, upun.

Agrio, tepei.

no-Agrio, tepeinite.

Agua, guag.

Agua fria, guag jochi, gochi.

Agua caliente, guay-cayo.

Agua salada, nanitag.

Aguada un poco, quietajin.

Aguardar, quieto matitc. Nipinoquioya.

Aguja, canu.

Agujerear, toyen, notoyen, notijo. Agusanarse, vosilam.

Ahi, aguay.

Ahogar del pescuezo, chocoo.

Ahogarse con agua, yquia.

Ahora, tajuaja-tana.

Ahorrar poquito, teigjua . Está ocinso, tetaijua.

Ay está, inacachi.

Ajuar, nocaigies, nocaies.

Ala, leg, pl. lejuis.

Alargar, cochoinucc.

Alazan, alechag.

Alcanzar lo caido, chumina, jumin .

Alegrarse, caglin.

Alegre, caglin, caylin.

Alentar, agtigquié. 
Alforjas, neinis, nocagnis.

Algarroba, yuay.

Algarroba negra, vosochag.

Algodon, guesatag.

Alma, ajat, pl. ajatas.

Alto, tooppa.

Alumbrar, utunquie.

Allá, iocachi.

Allá lójos, ydycadni.

Allá no muy lejos, ydcachi.

Alli, yllachi, nachi.

Amar, jumien, contra, cachi jumin.

Amarillo, catutag.

Amigo, yjua, yojua, jumenec.

Amontonar, ascontúu.

An muerto, ylaan; se ha muerto, yil.

Anda, vete, maa, maa $=a p i$, no matitc.

Anda á comer, mateec.

Andar, caminar, obelec, obest; Nobeleclin.

Andar á pié, asquia=noig.

Andar á caballo, abuté.

Anguila, añat.

Anta, hiclag.

Antes de ayer, aponag, agi. Yonag el nagi.

Anzuelo, quinag-chog-non.

Aorita, cayle, guatana.

Apagar el fuego ó vela, omet.

Apagarse, yon.

A partarse, aiacachis_alta.

Apasanca, yag-tag.

A pretado, tuunsti.

Apretar, aptit.

Apretar la carga, nuunti 3 tuunti.

A purar alguno, cayle=ezlin.

Aquel es, japtulechi.

Aquello, tag, tagchi. Macha; Jatalechi, aquello.

Aquellos, tajoslechi.

Aqui, caana.

Aquellos son, japatuglechi.

Araña, suguanlocuc.

Arar, osaji, gognet.

Arco, Juchag ( $L ?$ ) Yris Labo.

Arena, orotag.

Armado pescado, castac.

Arear, ocosla, ocoz, si arrean.

Arremangarse, aimpa.

Arriba, caspo, puule.

Arrimar, ain3 aama.

Arrodillarse, nocanquicte $=\mathrm{ch}$ i nen.

Arrojar, vomitar, nochuñct, vocoyi.
Arrugarse, sujuijo.

Arrugas, tesue.

Asar, otag.

Asesar, laiel.

Asi chiquito, fana.

Asi grande, panantag.

Asomarse, yaigno.

Atar, aytc.

Atras, yolejuct.

Atrasarse, imaglegem.

Aullar, anlin.

Aurora, yjualanle.

Avestruz, guanlac.

Ayer, yonag-agi.

Ayudar, quiota, chota.

Azadon, ygñatguie.

Azar ó flor de los árboles, Labo.

Azotar, aitas idlin.

Azotes, notaesnates.

Azuela, taingui .

Azul, yti, pl. yti-ctas.

\section{B}

Babas, guachun.

Baca, guaseta, ysan.

Bagre, guag-nolc.

Bailar, chazchuc.

Baina, legi.

Baja lo colgado, tagquia.

Bajarse, nonugquia.

Banon, nocala, la. Ver Baston.

Bañarse, nadar, nonai, nonaiji.

Barba, nouse.

Barbas, lepaset, pase.

Barbiquejo, yotac.

Barrenar, toyen.

Barreno, quinagtein.

Barrer, ajas, oubache.

Barriga, noche.

Barrigon, chetag.

Barro, ygnat, aset.

Basta, manteg.

Baston, nocala, la.

Batir, casoini.

Bautizado ó que tiene nombre, pazquie leije.

no-Bautizado, pazquie leijijinitc, leijijitc.

Bautizar, chaipeguag. Nooteya 2 tathia.

Bayo, catucuetag.

Beber, tuug, tujula. Quikno.

Bejiga, utuni.

Bejuco, lenaca.

Bela, nolet.

Besar, noichuglin, 2 chuglin, $3 \mathrm{Ni}$ signée. 
Besar la mano, noisign $=$ g. Quici. Blanco, pelag, pelagquietag, pl. pelaquietas; peelag.

Boca, nolagni, nolagi.- Abrir la boca, quiczajaji.

Bofes, lepujos.

Bolar, luumpa.

Bolsa, nocagni.

Borlas, nohiutac.

Borracho, tobocoy.-muy borracho, techogtag.

Bostezar, nocagquiesag.

Botones, noulelei.

Bueno, is.

P. Buenos dias compañero, ala, annenegi, anegi.

R. Buenos dias, antena.

P. Estás bueno, yaja is ?

R. Bueno, is istat.

Malo, hiel.

Sano, nolag.

Cansado, noyel.

P. Buenas noches compañero, ala, jonagnoig, is jonachi.

R. Buenas noches, camag noistat.

\section{C}

Caballo ensillado, lotag, loy. Caballo ensillado, abutc loy.

Cabar, yuagi gotnet, gonet.

Cabeza, litec.

Cabra, caila.

Cada uno, novegyaba, chanit.

Cadillo, tachoc.

Caerse, yquiagquia, thiatteen.

Cagita, gichuc.

Caja, nototile, nopu.

Calambre, yechegla, lequeilan-aitag.

Calentar algo, utunitigi itag.

Calentarse, utunlin, utuunlin jnytag.

Caldo, tobobii, tobobii.

Caliente, chagu. Remedio Nocathia.

Calor, chingilamo.

Calzones, nolacpois.

Callar, obtiin, obtheet, Calla, Quiet, Nitheet.

Cama, nojoet, nouet.

Camaras de sangre, chatitagilam.

Camino, naig; caminar, nucuenaig.

Camisa, sagal.

Camotes, yetig.

Canilla, nolile.

Cantar, cazchun.

Cantar las aves, yp, yplin.

Cañas, canujuiis.

Capar, nag, guianis. Nolagni. Leni chianis.
Capitan, niat.

Caracol, lel, pl. lelises.

Carancho, ajuchag.

Cargar, lanflin, tigpe, tépe.

Carne, ysam, guaseta.

Carrecor, tab pelaglin. (w)

Carrillo, noyalo.

Casa, lobuque, hoet.

Casarse, notejuaye, tejuaye, se ha casado.

Cascabel, quinagtelo.

Castigar, aitas, tasiglin.

Catarro, quictag.

Catorce, alocon.

Caxa de tocar, puutag.

Cedro, pagniquieteg.

Cera, jopa.

Cerco, notajuee.

Cerrar, ogni.

Cerrar la boca, no jutuec lagni. Ogni lagni.

Cerrar los ojos, nomapa.

Ciego, ténuc, aznam.

Cielo, pule, yopulei. Ytal ppe-lé.

Cielo de los bienaventurados, yopuley.

Ciervo, guase.

Cigarro, chuti.

Cinco, ype befagla, ypebeta, ijuantesii.

Cincha, nocachetag.

Claro, ycati, ysati, sii.

Clavar, cagquia, thinenthia.

Cocinar, nopenec=lac, voy á cocinar, nocatay.

Codo, nocáto, nocachite.

Cojo, calapojo; calavac.

Cola, leguias. Las partes, chanchiles, chawe.

Colar, sápi.

Colgar, neipa, tecapa. Estás, yaja.

Colorado, ychato, yquiat.

Comenzar, telapan, chiunpa.

Comer, tec.

Comezon tener, tec.

Comida, lac, noslac, uyé.

Cómo se llama? quivoslen

Compadecerse, lelachugiji

Componer, yélin, eenlin; los reñidos, enlilalin.

Comprar, achagle, ybolejaye. No cachaja.

Concebir, achochan

Concha chiquita, lenquictag.

Concha grande, leñec.

Conejo, macquia.

Confesarse, tapuya. Padre cainugias

Congojarse, tiguiunquic paam. Notichum. 
Conocer, tajueleg.

no-Conocer, tajueniegte.

Consolar, ajuyeg, Nocagslin.

Contar, notujuantes, Yamé, yanflin

Continuar, telajan, ylejan.

Contradecir, nejipate 2 Siichet 3 leche. Ybuct lanflin.

Convalecer, yláguic, la gente.

Conversar, tajuyguec.

Convidar, chiumien. Huewo, tisla yjuala.

Convidar á todos, huenagus.

Convocar, huigui.

Corazón, notogtle.

Cortar, unsit.

Cortar hasta la frente, noinsit notap.

Cortar hasta las orejas, noinsiz notasilis.

Cortarse el pelo de la corona noinsez guion litec.

Cortarse el hilo, yés.

Corzuela, chowe.

Corral, leji.

Correr, caile, maa.

Coser, nochec, chec.

Cosido, yo.

Cosquillas, ubalais.

Costillas, noisiglile.

Coto, nocachi.

Coton, nocayuquie.

Cozear, asei.

Crecer, hic=lapa, talac.

Crudo, lapag.

Cruzar los brazos, chujue lámig, chujuclec=acueg.

Cuatro, nocuepogec.

Cubrirse ó ponerse el sombrero, tipa cobowa.

Cuchillo, chodnet.

Cuello, nopane.

Cuerno, quin

Cuero, ag.

Cuervo, cheguóo, pl. cheguos.

Cuesta, lesug, pl. lesujuis.

Cuidar, huya ycay.

Culo, logueg.

Cumbrera, letec.

Cuña, osen.

Cuñada, nocátog.

Cuñado, nocalag.

Curar, tilanan. Ylágeg, ybolechaye.

Cuyo es esto? achicayguet.

Cuya es esta comida? achilac-tage? De Pedro, Pedro lac.

\section{Ch}

Chacara, cashoct, pl. ca=hoctes. Nocas. Chaguar, niag, niacu, comida, uyé.

Chaguar fruta, oyeglog.

Chala, yspet, oler.

Chancho, nichag, Satay, abúchag.

Chañar, lechinici.

Charquear, novocharqui, elel chauet.

Chasque, yquien 2 Silat 3 Niguayac.

Chicharron, notuglez.

Chifles, noglacuc, noslacucy.

Chilca, yuichanes.

Chinas, quileis.

Chincha. Ver Cincha.

Chiquito, lasáag.

Chispa, tegquiel.

Choclos, yspetcas.

Chorrear, tagloo.

Chucho, télag.

Chuña, niguici.

Chupar, nocha noquia=chule, chugni.

\section{D}

Dar, tis. Avendamo.

Dar presentando, huit gueno.

Darlo todo, maletuec.

Dedo, nojug, pl. Nojus.

Dedo gordo, nojug, loquetag.

De donde? qui?

De donde vienes? quilatagli chiletagli.

De la vanda, taluechié.

Dejar, manteg.

Delgado, linsag, pl. linsas.

Dentera, chipil.

Dentudo pescado, nijuc.

De quién es esso? achine tag? Achitagge?

Derecho, chupinguia.

Derramar, chai, chaig.

Derramarse, changuia.

Desgarrar la ropa, oglipe.

Desgranar, lenguic.

Desigual, suta numquie.

Desnudarse, nolini nohuc.

Desojar, tognequiela olec.

Desollar, ajec.

Despues, camag, agnis, lapag.

Desyervar, tognela tales.

Dia, yuala. Ytal iquala.

Dia claro, yguala tog.

Dia nublado, yjala pule inquia.

Diablo, ajatag. Gualac-lauc.

Dientes, nochete, pl. Nochetes.

Diez, lagelapleza.

Diez y seis, opou. 
Diez y siete, loos.

Dios, Tupa.

Divioso, lechi.

Doblar la ropa, cajuel.

Doblar las rodillas, nocanguiete nen. chi.

Doler, aytag.

Dolor, aytag, pl. aytas.

de Dónde? qui ?

por Dónde? qui ininucue? quilatagli ?

Dónde está, quicha.

Dónde está tu padre, (ha ido), chijoje Asthia.

Dorado, catuta.

Dormir, nolima. Lemma, Yma. Nocanguia.

Dos, tácuas.

Doze, natujuaya el.

Dulce, aconez, acag.

Duro, tuuwe.

\section{$\mathbf{E}$}

El caballo de Juan, Juan latag.

El menor, achinic.

El miembro, loö.

El otro, jape.

El cuento, laamet.

Emborracharse, tobocoy.

Empachado, atajuac.

Empacharse, a iajuac. Tujuac.

Encender, lagni, ugno.

Encias, nochote sanis.

En dónde? quineg, quicho?

Enfermar, aytasalam, tuug.

Enfermedad venerea, amotag, pl. amotas.

Enfermo, nisia, yel.

Enfrenar, tato locay.

Engañar, yueguienglin, yuecnacha.

Enseñar, chujuenlin.

Ensillar, enlin tatag.

Entender, nolatama.

no Entender, latitá áma.

Entrar, noy.

Es de Pedro esto? Pedro tagelechi? Pedro cayguet?

Escopeta, luchetag.

Escribir, lesairdlin.

Escuchar, yjoye.

Eslabon, itaguic.

Espantar, ocosa.

Espantarse, onochayá, nohag.

Espejo, souulag. Notuunti.

Espesar, nigui noquioya.

Espeso, notonec.

Espina, quitenil, pl. quitenis.

Espoloorcar, tato.
Esquin, chela.

Estar encatarrado,

Estar preñada, ahochan, 1, chohochan.

Estender, quigni.

Estirar bion, toone.

Esto, tagchi, Maca, atachi.

Estornudar, nocachien.

Estrella, catés.

\section{F}

Faxa, nocañiacu.

Faxarse, noyaitlami. Yuietlami.

Fiar, quiuncata, tisiapag.

Fiera cosa, cachia, site.

Flaco, lompen.

Flecha, lotec.

Flor, nabi).

Floxo, eguie. Notacaxinite; no apretado, cab cayno.

Fornicar, tuug, quileis. Gualaichag.

Forro, legi.

Freir, túleg, otieni.

Freno, locag.

Frente, notachio.

Fresada, poncho, pelatag.

Fruto recién cuajado, layjas.

Fuego, itag.

Fuero, caquietag, cachia.

Fuerte ó duro, tuum.

Fuerte, castillo, nojuec.

\section{G}

Galapago, tolcag.

Gallo, gallina, oö.

Ganar, chag, nocayaan.

Garrapata, Yueguiatag, pl. Yueguiatas.

Garguero, nopagni, 1, nocachi.

Garuar, tispetu.

Gato montés, silacay.

Gavilan, yesnag.

Gerga, guesag.

Gobernador, aputag.

Golondrina, yuichatas.

Gordo, yatag.

Gorro, nocabona.

Grande, ucag, lutag femenino.

Granizo, cataatu.

Grasa, agpe.

Grillo, tichiel.

Gualcas, Anis, 2 Lanis, 1 Nachacaj.

Gualcas amarillas de los indios, leltaje.

Guapo, amalag, notacagag.

Guardar, cáneg.

Guisar, nopen, nolac.

Gusanos, ivóós. 
H

Ha llegado? yeg nan?

Hablar, aboye.

Hablar en secreto, $b$ al oido, san. sameg.

Hablar á solas, tojuiase. que Hablas, quilaboye.

Hacer, enlin.

Hacha, etetoitay, pl, etetoitas.

Hachear, yuagi (J).

Hambre, chuyu.

Hasta mañana, nilag noig.

Haz comido al medio dia? yjualai, canitug?

Hechar, arrojar de sí, nojumée. Noticadmi.

Hechar ó poner, chano, chaipe.

Hechar tierra, o tapar el agujere, pogquie, chaigue.

Hermana, quite. Noguita.

Hermano, quila. Noguinig.

Hermano pequeño, notinic.

Hermoso, silentag. Ysia.

Hervir, naguai.

no Hervir, naguainite.

Hígado, tanec.

Hija, yase.

Hijito mio, yasa.

Hijito tuyo, aasa.

Hijo, yas.

Hijo de puta, yuctigue.

Hijos, leles. Nules.

Hilado, noponec.

Hilar, tié.

Hilo, nocheg-nacates.

Hipo, yogle.

Hombre, ynoon.

Hombre, noon.

el Hombre, I noon.

del Hombre, y noon.

para el Hombre, y noon.

los Hombres, ynolas.

Honda, nocajuti.

Hondo, pilog.

Hormiga, sugulac, pl. suguanes.

Hoy, hijualane. Ytal, icualanna.

Huerfano, Ponag. Nemec.

Hueso, litc, pl. licta.

Huevo, liguiu.

Huir, yan.

Humareda, tu chetag.

Humear, nojuac.

Humo, tuchag.
Igual, teliguiguic.

Incordio, ybotia amotag.

Indio, ynoon, pl. ynolas.

Indio bueno, noon is.

Irse, yapi, lobes, lobelec. no quiere ir, yquite, netag.

Jugar, coige.

Juntarse, nojutuec.

Juntos, jutuec.

\section{$\mathbf{L}$}

Labios, nopaset. Nopaste.

La casa del Padre es buena, Pale 10bucua is.

Ladron, etanchag, yeaten.

Lagartija, quiala.

Lágrimas, notet=ii.

Lana, noolci, yic.

Langosta voladora, chol satoma Pana.

Lanza, yuum.

Lapacho, obtac.

Largo, pitag.

Las partes (de la Cola), chanchiles, chauc.

Lavar, lejo, 1, noleg, 1, leg.

Lazo, nocabotag, 1 , chidaguiltag .

Lechiguana, nobelec.

Lechuza, quiliguiac.

Leer, noyaidni.

Lejos, tojoe, tojoy.

Lengua, nocagliguiu.

Lenguia, idioma, leine.

Leña, la.

Leon, ogualag.

Levantar arriba alguna, quicyaspa.

Levantarse, nipa, l, neguicpa.

Libro, nojuguienec.

Liendres, ysato, obat $=\mathrm{li}$.

Ligero, guajadlin.

Limon, achag, pl. achetas.

Limpiar, isato, obat iis.

Lindo, silentag, 1, yojuan.

Lobo, latatag.

Lomillos, quiapa.

Lomillos de los indios, nojouet.

Los otros, naam.

Luna, guela. Ytal. iguelách.

Luna nueva, guelatal.

Luna llena, guelatac poyeg.

Luna menguante, pagla.

Luna clara, guelas. 
Luz, yjuala.

Luz de la vela, notiet.

\section{LI}

Llamar, agne.

cómo te Llaman? agne ami?

cómo te Llamas? qui volin?

Llano, isguic.

no Llano, quienas.

Llave, nopequiia. Nopethia.

Llegar dealguna parte, naan.

Llenar, aneg, ontepoyeg.

Lleno, tepoye.

Llorar, teglin.

Llover, yhongutla.

M

Macana, nocuenez.

c-Madre, jacob, lacoo.

Madrugar, nepa, lelentag.

Maduro, aloxa tepeigino, tepeinitc.

Maiz, yspet.

Malo, chache, cachia, 1, sitc, 1, nisia.

Manantial, chijuic, junet.

Mandar, cheẻn.

Mango, ut. Lejuapo=chag.

Mano, noguei.

Mano derecha, nochancat.

Mano izquierda, nojoncat.

Mañana, yjuala. Ytal. icuala.

pasado Mañana, yjuala eb.

de Mañana ó muy temprano, nemitag, 1, niguianet.

Marido 6 mujer, chejua. Le chejuac.

Mariposa, chocoz.

Marlo, ispetlilé.

Mataco, Anal, pl. Analeys.

Mataguayo, Taglele, pl. Tagleleis.

Matar, ylaan, laam.

Matos, chochones.

Mear, tuul.

Mediar, nocajapotes.

Menear, choglin.

Mentir, anchaglin, 1, yanflin. Nositabo.

Mentira, anchaglin, 1, gueteanflin.

Mesa, nolauet. Noueteslay.

Meter, vidgute, vitouit.

Meter adentro ó llevar aden-

tro, anchaguinp.

Mezquino, chognag, chogneteg.
Miedo, onohaya, noai.

no-Miedo, onohaya-nite.

Miel, pinu.

Mierda, ramuc, 1, aca.

Mi tío, leey.

Mio, nocátag, noeay, ycayguet, nocatagi.

Mis parientes, iaaiñac.

Mis hijos, yleés; tuyos, aleés.

Mistol, ajayag.

Mitad, loota.

Mocos, nocaguialtag.

Mojarras, ajuetes.

Mojarse, notacagli, 1, nocaglien.

Moler, quionguan, chojuac.

Monta á caballo, nupa: latag. Ynupe epélatg.

Monte, teigji.

Monte grande, teijitag.

Moral, jinag, cachitag. Lacue.

Morcillos de los brazos, nocueche.

Morder, yocuag.

Morera, techuc.

Morir, yl.

Morirá, inila.

Mortero, yuelic.

Mosca, atac, pl. atas.

Mosquitos, yuinetés.

Mostrar alguna cosa, pina, paina. Tigigi.

Mote, noponec.

Moza, lucha.

Mozo, magse, pl. magses. Mansi.

Muchachos, naches.

Muchos, loos.

Muerto 6 difunto, ylneen. Ajaat.

Muñeca, nocucbo.

Murciélago, asus.

Muslo, noleguic. Leche.

\section{$\mathbf{N}$}

Nacer (planta), talg.

Nacer (gente, animal), capuchan.

Nada, maic.

Nadar, nonaig, l, nonaigi. Naay.

Nalgas, logueg chalos.

Naranja, achelag, pl. achetas.

Narices, nonus.

Navaja, najucl.

Negro, chalag, 1, chalagita, shelag.

Niebla, tuchag, 1, tuchetag.

Nieta, yguiaya.

Nieto, yuilayas. Nouaela. Yohayas.

No, ca, l, ama. Ytal $K d$.

No hay, novainita. 
Noche, yonaachi.

Nombre, noley.

Nosotros, lemeil, namil.

Nubes, pulc, calatu.

Nublado, yuicheec.

Nudos, nocochoim.

Nudos de los dedos, najuscocho.

Nuestro, nemil. Ycaguet. Nocayguet.

Nueve, naya.

Nuevo, neguiachic. Nethaec.

Nutria, analatag.

\section{$\tilde{\mathbf{N}}$}

Ñato, nonus cho, 1, nonus choguiag.

\section{$\mathbf{0}$}

Obscuro, yonachi, vuu.

muy Obscuro, yonachi ugia.

Ocho, najaela.

Oir, latne-ama, 1, lata.

Ojala, yajay! jaá.

Ojas, noolcc.

Ojo, notelo.

Oler, ysineg.

Olvidar, nopetula. Ghovalia.

Olla, tobcg.

Ombligo, nochac.

Ombro, noti. Nojuapo.

Once, yjuantesii.

Orcon, nocachutc.

Orejas, noguiotc.

Oso hormiguero, suulag.

Otra vez, achugquic.

Otra, otra, el.

Oveja, chonetag.

\section{$\mathbf{P}$}

Pacará, guatog.

Pacu, yuctac.

Padre, yequia, ysquia, ysthia.

Pagar, olajaya, ybonlalajaya.

Paja vup.

Pala, lat-ag.

Palma de la mano, nocuccho.

Palma árbol, yuichue.

Palmar, yuichucue.

Palo, la.

Palo santo, yooc.

Palo borracho, chenlac=chile.

Paloma, cachitag.

Paloma chiquita, chipup.

Paloma del campo, chulu.

Paloma grande, poperí.

Pampa, alotag.

Pan, tantan, l, tenten.
Pantorrilla, nocaliche.

Panza, noché, l, leche.

Pañuelo, nocaguiectag quia.

Papas, nasuc.

Papas del monte, lenac.

Papel, noyape. Nujuquienec.

Para el hombre, nola-lac.

Para Antonio, Autonio-lac.

Pararse, ó estar en pié, cásit.

Parco, nagquiuyaja.

Pared, ygñat.

Parir, puu, capuchan.

Pasear, Obelec, 1, obes, 1, nolenlin.

Pata, nocala.

Pato, blanco, yoquictag.

Pato negro, ascan.

Pato chiquito, ycleni.

Patron, ybuc.

Pava del monte, estajuctag.

Pecho, notoque, notuguc.

Pedir, noslla, asla, notala.

Pedir licencia, ó avisar, vasilote.

Pedo, notugcaz.

Peer, agtuc.

Pegarse, seteg.

Peinarse, nosit, leteg.

Peine, chonig.

Pelar ó quitar la cáscara, yenguietajes.

Pelear, licat titi hium, notaglo.

Pelo, noolee.

Pendiente, noguiotele.

Peones, nochumienec. nocainom.

Pequeño, lasag.

Perderse alguna cosa, tetaig, pl. tetaiglin. Nogueti.

Perro, signag.

Perro ligero, snag, guajalin:

Perro, sinag, pl. sinas.

Pesado, tílagpa.

Pesado, ó no ligero.

Pesar, tiglapa, ytitnum.

Pescado, yagset, pl. yagsetes.

Pescar con red, abocoy.

Pescar con flecha, tiacan.

Pescuezo, nabo, nabotes, pagni.

Petaca, nocagni. Nocluuc.

Pezon, ac.

Picaro, y tayeg.

Pico de las aves, paset.

Piedra, tuunte.

Pies, nopachio.

Pintarse, ylen, hoaytag.

Pisar, aspo, aso.

Pisar ó apretar la tierra, choguegguie gognet.

Plata, colque. 
Plato, aset, chapel, quinag. Pluma.

Plumar, chiguititas, lejuya.

Pobre, lichag.

muy Pobre, lichag, jajucim.

Poco á poco, atagnan, atagnanflin.

Podrido, najut.

Podrirse, nojuti.

Pon, tigi.

Poner en algun lugar, tinacachi, l, aigi.

Poner adelante, ajoye. Majoy". letagiig.

Ponerse atras, jolejutc.

Poquito, quinsag.

Por alli, yninucucho.

Por donde, quinunucuc.

Porongo, bochotag.

Porongo de avejas, yeclag.

Porotos, anictag.

Porque, ziquiac.

estar Preñada, ahochan, 1, chohochan.

Prestar, noguiejaneg, chojantieg.

Prestar, dar gratuitamente, nogueno.

Presto, guatana, vaile. Aloxa.

Primero, nequela.

Puerta, nope=ot.

Pulga, signagvos.

Pulvera, nocuc, ojuata.

Puna, lepes.

\section{$\mathbf{Q}$}

Quando se fué, pacchimenti.

Quando irá, quina atoic.

Quándo te vas? ciatagateglelec, chiategelapi.

Quándo vendrås? quilajaleglenan?

Quándo vás ? quiajate Jecjec?

Quanto, quiaxati.

Quánto ? chajatec?

Quarto, tujuan.

Quatro, nocucpoigyec.

Qué más ? chiel, quiinac?

Qué es lo que? achimayeg?

Qué es eso? achumagchi. Quiapajac.

Qué trahes? ataglechag.

Quebrado, poxo, poxotas.

Quebrar, non=macas, echa.

Quebrarse, poxo, sayec.

Quemar, tiag-tuug, nooyo. Labag.

Querer, junin, ajuminitage, yjumin. no-Querer, yjuminite, nujunite.

Queso, guasetacathos.

Quién? achitagehí.
Quien es ese, achinag-chitagchi.

Quién es aquel, achitaglechi?

Quién es ese? achipi, achitape.

Quién esto trae? achitag-pa.

Quinto, yjuantesi.

Quinze, naya.

Quirquincho, oguanag, teiatag.

Quitar, yscat, etanchag, pl. ycaten. no-Quitar, camaiscat.

Quitarse el sombrero, tacguiacabona.

Quitataco, natal.

Quixada (j), nochaloslie.

IR

Rabon, chopo.

Rajar, yuagquie.

Rajarse, poxo.

Rascarse, chiasma.

Raspar, ajas.

Raton, amat.

Raya, pescado, pogni, taajan.

Rayo, yuíchecyag.

Reventar, poxo.

Red, otama.

Redondo, letoig, tonlaglin.

Regalar, huitnoguem.

Regoldar, nopat, alujuac, cojuc, coujua.

Reir, esguieili.

Relámpago, yoclep.

Remendar, toy, cheec.

Remolino, guc, saiontag.

Rempujar, nugguic, yomec.

Reñir, yglin.

Rincon, lacaucu.

Río, tecta.

Río corriente, tecta ilajucche.

Río manso, tecta ilajucnijuctic, tetaciin.

Río crecido, tectapoig, tetacuug.

Robar, yscat, etanchag.

Robal, pescado, tachucuita.

Rocio, ajas, yas.

Rodilla, nocanguicte.

Romper, queisag, lequies, chesaag .

Sabalo, cheinat.

Saber, yaneg, nijaneyec, taig, tetag.

no-Saber, yjanicte.

Sacar, leni.

no-Sacar, leniijijinitc.

Sacudía, siquiat.

Sal, núpa.

Saliva, laguiel, nolachil. 
Salivar, nojuachug.

Sandia, suvélac.

Sangre, voys.

Sano, is.

Sapo, tagna.

Sarna, quiesag.

Secarse, tecnhiac.

Secarse ó cortarse el agua, ynguas.

Seguir á otro, moquel. Yjuic.

Segundo, eei.

Sed (tener), noquiin, negelan, yctun.

Seis, todajinta.

Sembrar, tuudguic.

ya-Sembré, pacquic noludguic.

Semilla, nocás, looy, nocaslooy.

Sentado, pápa, pajiempa.

Sesos, letigla.

Sebil, ajec.

Sevo, agla.

Si, ic.

Sidras, achctatas.

Siete, loosi.

Silvar, yoc piin.

Silla, nohueghuet.

Sobaco, nubilicho.

Sobremesa de chaguar, siguiet.

Sobrino, nohacla.

Sobrina, lénig, 1, lenijua.

Sol, yjuaba, yjuala. Ytal iqua'a

Soldado, chistiano, ajalag.

Solo, tangua.

Sombra, na, nupel.

Sombrero, nocabona.

Sonsera, cainogia.

Sonso, suuc, ysuc, pl. Sucuis.

Soplar, ajuthi.

ordo chototoio

Sortija, nojugni. nojugi. Mio, icao bo. Tuyo, acubona. Del otro, atalechi.

Subir, nupa =cupa.

Sucio, yguiono, l, yguiorlin.

Sudor, tacagli, l, chiug, chuugaitag. Suegro, nocachati.

Suelo, setag, siteg.

Sueño, negéti.

Surubi, quiuncacu.

Suspirar, aloblitag, leyalebompa

Suyo (cuando la cosa es viviente), la, pl. lay

Suyo (quando...), cay, pl. caigies.

\section{$\mathbf{T}$}

Tabaco, yocos, 1, yocuas.

Tábano, lacas.

Talega de chaguar, nihilux.

Taparse, ope.
Tapon, lopet.

Tarde, yonag.

Tases, gualaup.

Tela de araña, chiojocsac.

Tender, quicgni.

Tener, yguen, 1, noguen. Ytal $n \boldsymbol{u}$. hun ho.

no-Tener, novainita, 1, nota. Ytal. hueni-tdé nou-ho.

Tener verguenza, nojucl.

Tener sed, negelanpilian. Nogtlin.

Tener frio, yuletilanno.

Tener calor, chingilanno.

Tener miedo, onohaga.

no-Tener miedo, ohonohagnietc.

Tener de alguna cosa, choc.

Tener, ambre.

Tercera, eeltaxe.

Tetas, notate.

Tejer, nohuc, tii.

Tierra, gognet.

Tigre, yag.

Tinaja, yate.

Tío, lay.

Tirar ó botar alguna cosa' yúmeg.

Tirar ó disparar alguna cosa, tiag.

Tirar de alguna cosa, togne, toan.

Tijera, aintacuy.

Toba, Guanlag.

Tobillo, nocasopi.

Tocar, aag calagay.

Todos, aaguc nequicg, oènec.

Tomar, chuma, choc.

Torcido, chcgueglin.

Tordillo, shagquic.

Toser, guicltagilan.

Trabajador bueno, nota, cajui.

Trabajar, chuglin.

Tragon, yalcaltag.

Traher, chag, achag.

Trampa, lainlele.

Trenzar, pachinquic.

Tres, tacuya.

Trece, yaspe.

Tripas, casle.

Triste, oblitag.

no-Triste, oblitagjite.

Tropezar, napan.

Trueno, yplin.

$\mathrm{Tu}$, aam, apam, japeem.

Tu hermano, athila.

Tu hermana, nochila, nolas.

Tuyo, yr, acaiguet, acatag.

Tus parientes, aaiñac.

Tu tîo, éléy. 


\section{$\mathbf{U}$}

Ubre, chachos.

Ultimo, lidjoo.

Uno, befagla.

Untar, ylegeg.

Uña, nojugtag, p1. nojustajes.

Uron, ylaa.

Urundel, antac.

Vaho, nojuac.

Vamos, neec; mayaneec, todos vamos.

adonde Vas? quilajoje, chilalajoje.

cuándo te Vas? ciat a gat e gle=lec, chiatelegapi.

Vaso, noglati.

Vasura, Ilamuc.

r.o te Vayas, mathite.

Vejoso, Tatho, pl. Tactunes.

Ven acá, acocana, luum, nitié.

Vena, nosat.

cuando Vendrás? quilategle nan.

Venir, niet, noye, atha, achina, ocaja, á las ? que vengan, ynonijocana á los hombres.

no quiere Venir, nétag, ne'fuitag, neiquite.

cuándo has Venido? quinajate-lenan? Ver, yjuen.

Verdad, meet. Ytal mat, cierto.

no Verdad, meetite. Ytal $m a$ $t t i-t d e ́$, falso.

Verdad, achun.

Verde Jerba ó planta, guachan.

Vestirse, odla-ienlin.

Vete, ma, maapi.

Viejo, chiut.

Vieja, pescado, chiguitag, chiutag.

indio viejo, yuayug. de dónde Vienes? quilatagli, chiletagli.

Viento, ynjuac.

mucho Viento, ynguacuetag.

Viruelas, chiutagquic, chiutagchic.

Viuda, tesa, pl. tesales.

Viudo, nate, pl. nateles.

Vivoras, anlag.

Vivora, ylai ile.

Volver $b$ venir adonde se sale, tepil. Nan, tepil-la.

Volver del otro lado alguna cosa, tilaglipeel.

Volver ó repetir, achagguic.

Volver á todos lados, dar vueltas, notuclin.

Vomitar, nochuñet.

Vosotros, amey, yehi.

Voy, yapi, hic.

Vuelve presto, caile laame.

\section{$\mathbf{Y}$}

Yacaré, alutag.

Yervas, latales.

Yerro, nojayenec.

Yesquero, nocaitaglac.

Yguana, aluche.

Yo soy, yam me jaapian, $\boldsymbol{n}$.

Yo, yapian.

Yo, yaan.

Yo soy, japian; tu eres, japenage eem; aquel es, japtulechi; nosolios somos, janoslemeil; vosotros sois, japemeyu; aquellos son, japaluglechi.

\section{$\mathbf{Z}$}

Zancudos, yapina.

Zapallo, esguin, pl. esquinas.

Zapallo negro, aniotag.

Zapato, nisa, pl. nisas.

Zeniza, ytag moc, macaotag.

Zenza, lupuc.

Zepo, noponte.

Zorro, mau, tasloc. 


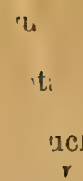

Lafone Quevedo, Dialecto Vejoz Boletin Del inst. geograf. ARG., tomo xvi.

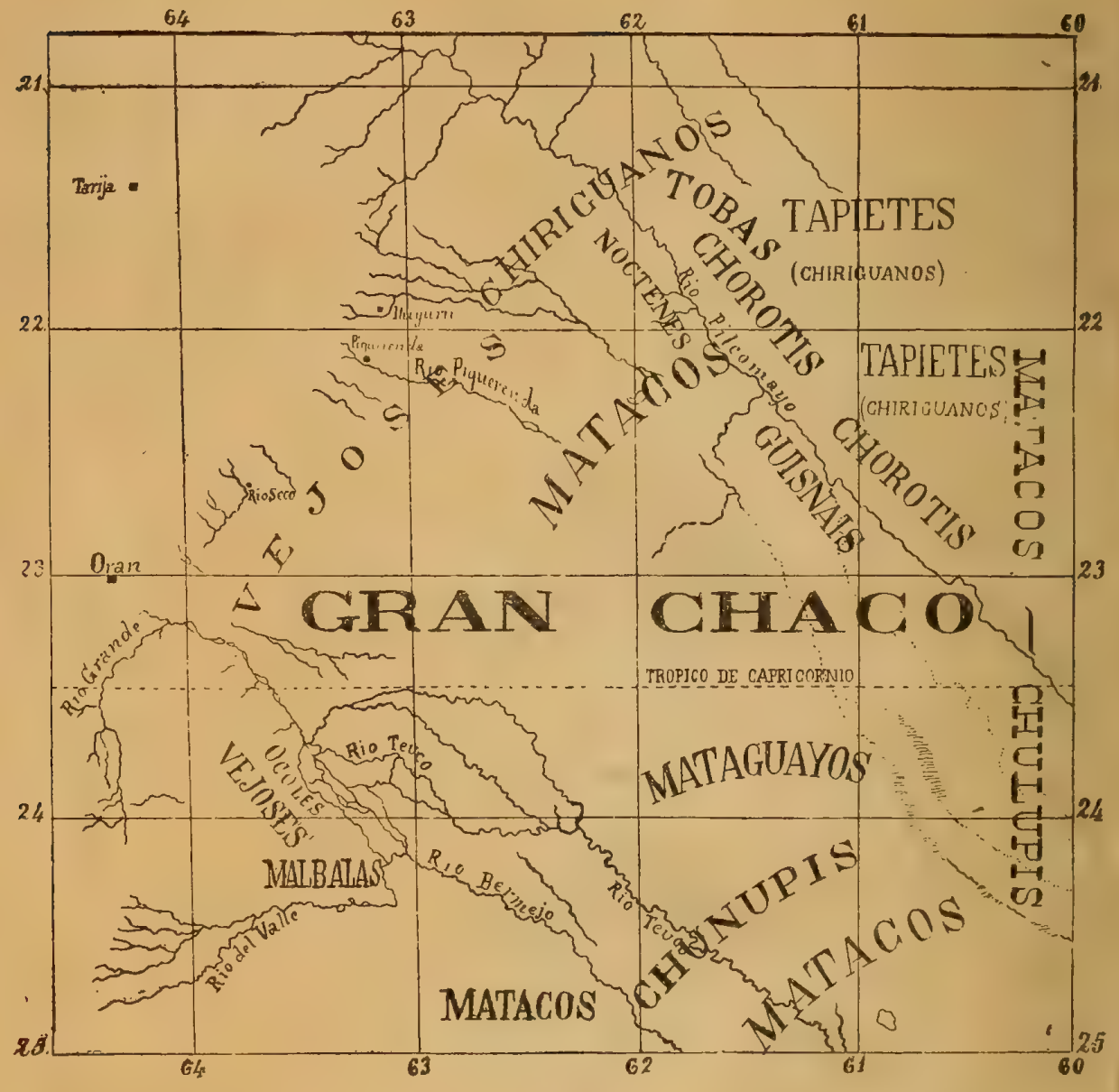

MAPA ETNICO

de las Tribus Mataco-Mataguayos del Gran Chaco, según carta del P. Giomocchini y mapa,s del P. Corrado y del Instituto Geográfico Argentino, por Samuel A. Lafone Quevedo. 


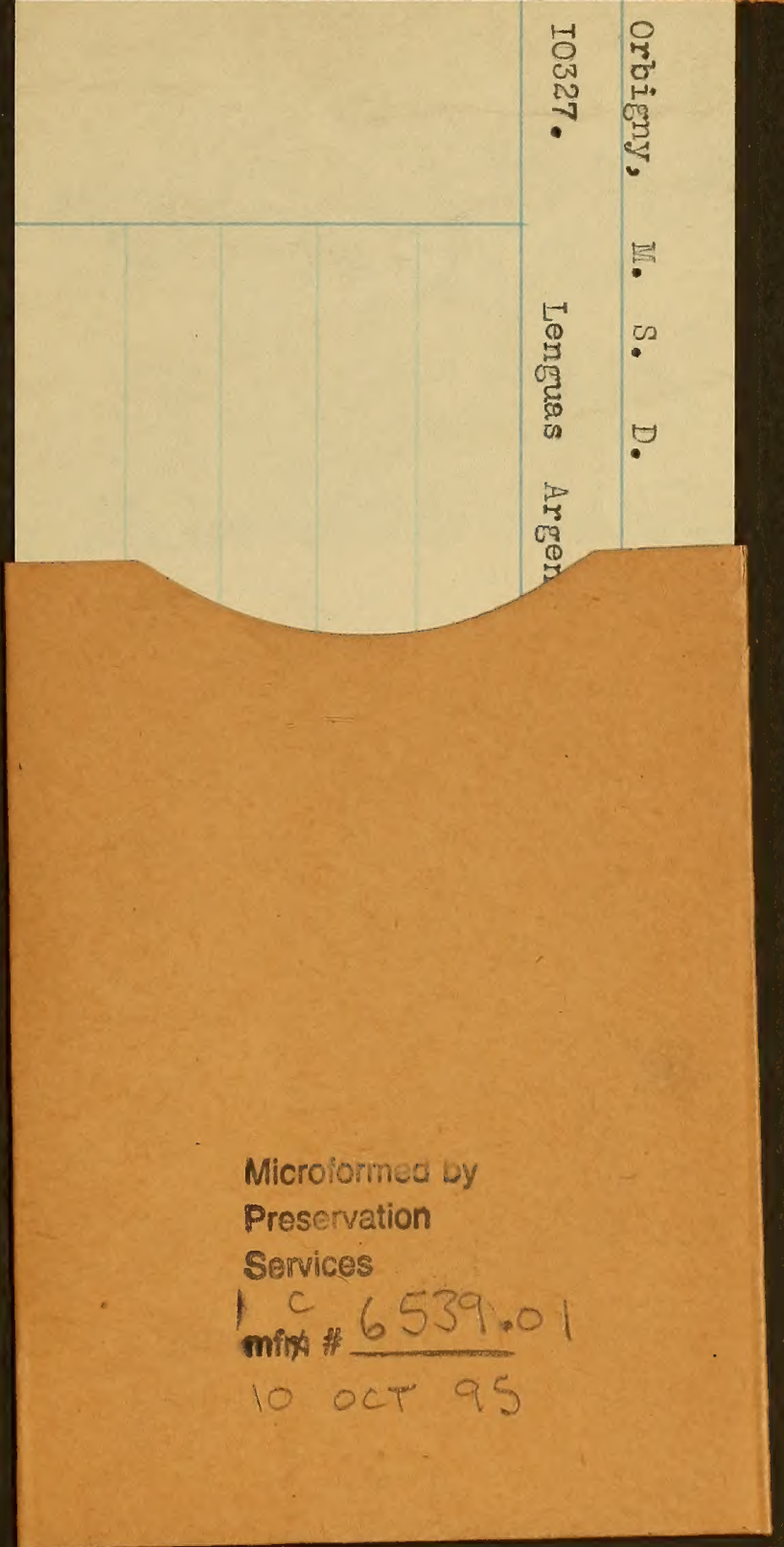




